\title{
O PAPEL DA CULTURA NA LÍNGUA(GEM) E NA COGNIÇÃO
}

\author{
Daniel L. EVERETT ID $\boldsymbol{~}$ \\ Department of Natural and Applied Sciences - Bentley University
}

\section{RESUMO}

Este trabalho apresenta um panorama de algumas pesquisas a respeito de como a cultura está relacionada de forma causal com o entendimento da cognição humana. Particularmente, avalio estudos a respeito da influência da cultura na memória de curto prazo, na percepção visual, na gramática, na cognição numérica, e na evolução linguística. Além disso, apresento um desiderato de metodologias sobre as conexões entre cultura e cognição, e um direcionamento para pesquisas futuras.

\section{ช}

\section{OPEN ACCESS}

EDITADO POR

- Miguel Oliveira, Jr. (UFAL)

- René Almeida (UFS)

REVISADO POR

- Januacele da Costa (UFAL)

- Ana Suelly Cabral (UnB)

TRADUZIDO POR

- Raquel D'Elboux Couto Nunes (UFAL)

DATAS

- Recebido: 03/01/2020

- Aceito: 17/03/2020

- Publicado: 09/07/2020

\section{COMO CITAR}

EVERETT, Daniel L. (2020). O papel da cultura na língua(gem) e na cognição. Cadernos de Linguística, v. 1, n. 1, p. 0137.

\section{ABSTRACT}

This paper provides an overview of some recent research on how culture is causally implicated in the understanding of human cognition. In particular, I review studies on the influence of culture on short-term memory, visual perception, grammar, numerical cognition, and language evolution. I also provide a list of desiderata for research methodologies on the connections between culture and cognition and a direction for future research.

\section{PALAVRAS-CHAVE}

Cultura; Língua; Pirahã; Sintaxe; Percepção; Evolução; Recursividade.

\section{KEYWORDS}

Culture; Language; Pirahã; Syntax; Perception; Evolution; Recursion. 
"O efeito da seleção natural no homem provavelmente tem sido tornar sem importância as diferenças genotípicas em traços de personalidade entre indivíduos e, particularmente, entre raças, em comparação à plasticidade fenotípica. Em vez de ter as respostas geneticamente fixas como em outras espécies animais, o homem é uma espécie que inventa suas próprias reações. E por meio dessa habilidade singular de inventar, improvisar as respostas, que nasce a cultura" (DOBZHANSKY, 1962). ${ }^{1}$

\section{INTRODUÇÃO}

Vários filósofos argumentaram que existe o chamado "conhecimento compartilhado", e.g. Seeman (2012). Ocasionalmente, eles afirmam isso metaforicamente, o que é até melhor, pois a ideia de conhecimento compartilhado não pode estar correta, literalmente. Não existe uma ideia que esteja na minha cabeça e na sua, da mesma maneira, ou utilizada por mim e depois por você, como uma meia, ou ocupada simultaneamente, como uma casa compartilhada. Duas ou mais pessoas podem, logicamente, pensar em dois "tokens" (não idênticos) de um único tipo de ideia, simultaneamente, em razão de um projeto ou por acaso, mas nunca a ideia é exatamente a mesma. Esses pensamentos sobrepostos, ou "pensamentos semelhantes", são uma condição necessária para a cultura. Porém, a noção de compartilhar ideias não é. Esse compartilhamento de ideias obscurece o entendimento de pensamentos semelhantes. Apesar de os pensamentos semelhantes não serem em si a cultura, eles são reflexos dela e também subjacentes a ela.

Não idênticos, mas similares, os pensamentos sobrepostos surgem pela simples razão de que as pessoas desenvolvem o conhecimento em contextos específicos, por meio de apercepções (EVERETT, 2016), reagindo às suas experiências, em parte ao imitar reações de pessoas a seu redor, em situações aparentemente similares (BOYD; RICHERSON, 1998; 2005). ${ }^{2}$ Esse conhecimento individual pode ser escondido ou ostensivo, sujeito a reflexão consciente ou a compartilhamento social, ou não. Chamo de "matéria escura da mente" o armazenamento individual, especialmente do geralmente não falado ou inefável (EVERETT, 2016). A sobreposição massiva em conhecimento individual e valores numa sociedade é o resultado de se concluir, por meio do consenso (tácito) da observação e da imitação, a respeito de que tipos de ideias, representadas como "tokens" em indivíduos, são socialmente endossadas, ou são simplesmente mais comuns.

1 N. da T.: As traduções das citações foram realizadas por mim (exceto em trechos com referências a outras traduções), com a finalidade de publicação deste trabalho.

2 Uma "apercepção" é o processo mental pelo qual as pessoas dão sentido a uma ideia, ao assimilá-la ao corpo de ideias que já possuem. 
No entanto, descobrir o que as pessoas estão pensando intra ou interculturalmente não é nem um pouco fácil, como filósofos, de forma até melhor do que antropólogos ou linguistas, frequentemente reconheceram. Christopher Hookway resume o problema:

\begin{abstract}
Antropólogos frequentemente tentam atribuir crenças e desejos aos membros de tribos estrangeiras que estão estudando: esperam garantir um entendimento do comportamento dos estrangeiros, ao atribuir várias atitudes cognitivas a eles e fornecer interpretações para a língua que usam. Parece que a teoria da interpretação é prejudicada pela evidência não intencional que está disponível - isso pode dar vazão ao ceticismo sobre a possibilidade do tipo de conhecimento de outras culturas, prometido pelo antropólogo (HOOKWAY, 1978, p. 17).
\end{abstract}

De fato, esse ceticismo aumenta quando reconhecemos que os membros de determinada cultura não têm, por si, total ciência do que sabem. Esse é o problema da "matéria escura", que defino da seguinte forma:

\begin{abstract}
A matéria escura da mente é qualquer conhecimento de como ou de quê, não falado em circunstâncias normais, geralmente não articulado até para nós mesmos. Pode ser, mas não é necessariamente, inefável. Emerge do atuar, do "processo cultural", e da "lingualização", enquanto aprendemos convenções e organização de conhecimento, e adotamos propriedades e ordenamentos de valores. É compartilhado e pessoal. Vem por meio de emicização, apercepções e memória, e assim produz nosso senso de "self" (EVERETT, 2016, p. 1).
\end{abstract}

Um exemplo simples de matéria escura é como andamos. Muitas pessoas ocidentais andam lado a lado com amigos pela calçada. Esse é um uso ineficiente do espaço, que com frequência faz as pessoas que andam em sentido contrário saírem fora da calçada, em direção à rua ou a um gramado. Na Amazônia, na selva e na vila (onde há bastante espaço para andar lado a lado), em muitos grupos as pessoas caminham em fila única. Isso se aprende com exemplos, e é um caso de como nós não sabemos que sabemos ou porque fazemos alguma coisa. É parte de nossa "matéria escura".

Essa definição é parcialmente influenciada pelo trabalho de Brandom (1994), segundo o qual entendemos que sentenças têm certos significados porque sabemos como usá-las, o que confere ao entendimento uma forma de ação. Todas as nossas ações são motivadas por alguma forma de matéria escura, embora talvez não sejamos capazes de expressar o que nos impulsiona linguisticamente (assim como geralmente não somos capazes de explicar porque variamos nossas articulações de consoantes em certas posições, em seu ambiente fonético, porque escolhemos certa bicicleta em diferentes modalidades de ciclismo, ou porque escrevemos de forma clara ou vaga). Muitos tipos e "tokens" de coisas que conhecemos, com base na regularidade de nossos comportamentos, são subconscientes ou inconscientes, e frequentemente não temos conhecimento de que sabemos essas coisas. E mesmo que tivéssemos, é provável que não soubéssemos dizer o que exatamente sabemos. A matéria escura é simbioticamente relacionada à cultura, no sentido de que está restrita socialmente e de que produz os valores ranqueados necessários, estruturas de conhecimento, e papéis sociais como resultado: 


\begin{abstract}
Cultura é uma rede abstrata moldando e conectando papéis sociais, domínios de conhecimento hierarquicamente estruturados e valores ranqueados. A cultura é dinâmica, mutável, reinterpretada momento a momento. Os papéis, o conhecimento e os valores da cultura são somente encontrados nos corpos (o cérebro é parte do corpo) e nos comportamentos de seus membros. A cultura permeia o indivíduo, a comunidade, os comportamentos e o pensamento (EVERETT, 2016, p. 66). ${ }^{3}$
\end{abstract}

Segundo argumentou Quine (1960), somente podemos interpretar o conhecimento - a partir de significados de palavras, significados de frases e além delas - como partes de discursos ou teorias mais amplos. Isso se deve parcialmente ao porquê de o "conhecimento tácito" (POLANYI, 2009) frequentemente se referir a ações ("lingualização" e "processo cultural”), em vez de a estados estáticos (com substantivos como "linguagem”). A emicização, por definição, ${ }^{4}$ refere-se a adotar, para nos moldar, as visões (tipos de ideias) de membros de nossa comunidade. Esse é o componente do processo de aprendizagem que acarreta a visão e a interpretação do mundo por meio da sobreposição, frequentemente quase idêntica, de estruturas de valores, papéis sociais e estruturas de conhecimento. A emicização, crucialmente, é o que faz possíveis as sentenças analíticas ou, ao menos, faz com que elas pareçam tão fortes. Essas sentenças se enquadram na nossa maneira de pensar, o que faz parecer que elas não têm alternativas (QUINE, 1960).

A cultura é parcialmente manifestada em papéis sociais, tais quais minha identidade agora como autor, e a sua, como leitor. A cultura é encontrada na minha forte preferência pela saúde à ingestão diária de alimentos altamente calóricos. (Sei que isso é cultural. Por exemplo, um caçador-coletor não faria avaliação desse alimento em seu ambiente nativo, a menos que fosse muito exposto a ele, ou que tomasse ciência de seus efeitos nocivos para a saúde, quando consumidos excessivamente etc.). Entretanto, a cultura não é encontrada "lá fora", i.e., fora de nossos corpos. Está localizada em comportamentos individuais (inclusive comportamentos verbais) e na matéria escura subjacente a tais comportamentos. A cultura é uma entidade hipotética que conecta indiví-

3 N. da T.: EVERETT, Daniel. Linguagem: a história da maior invenção da humanidade. São Paulo: Contexto, 2019.

4 A emicização surge do trabalho de Pike sobre êmico vs. ético. O autor cunhou essas palavras, com base nos termos linguísticos amplamente utilizados, fonético vs. fonêmico. A fonética (articulatória, acústica ou auditiva) é o estudo dos sons da fala da perspectiva de um falante não nativo, por exemplo, um físico ou um linguista. A fonêmica é o estudo de conjuntos de sons fonéticos que falantes nativos percebem como sons únicos, i.e., os sons importantes da perspectiva do falante nativo, de alguém de dentro. Por exemplo, todos os falantes de língua inglesa ouvem um som /p/ nas palavras [park], [spark], e [carp], quando na verdade há pelo menos três sons, todos escritos como ' $p$ ' nessas palavras, a saber, $\left[p^{h}\right],[p], e\left[p^{-}\right]$, respectivamente. Falantes nativos, portanto, sabem menos explicitamente do que tacitamente sobre os sons de sua língua, uma vez que falantes em geral nunca percebem os sons éticos separados, mas somente o único som êmico com o qual se associa um som ético. Entretanto, nunca confundem os sons éticos no uso. Consequentemente, apesar de faltar aos falantes nativos o conhecimento explícito da distribuição dos sons éticos de sua língua, e.g. as três manifestações separadas (tecnicamente, alofones) do /p/ nos exemplos acima mencionados, seu próprio conhecimento êmico produz comportamentos que podem ser descritos como "usar [p] em posições de sílaba medial, [p"] em (algumas) posições de sílaba inicial, e $\left[p^{\urcorner}\right]$na posição de final da frase”. 
duos múltiplos, mas somente por meio da abstração. Somente por meio da generalização, por comportamentos sobrepostos, é que faz sentido uma "cultura compartilhada".

Por que precisamos de tais conceitos no estudo da cognição humana? Há várias razões. Além do fato de que tais definições são úteis na antropologia, a "cultura" e a matéria escura se relacionam de forma causal com a cognição (e vice-versa. Exploro mais adiante isso neste trabalho). Os componentes da cultura elencados na minha definição nos ajudam a entender qual é o objeto a respeito do qual se deve chegar a um consen$\mathrm{so}^{5}$ (de forma ampla, uma cultura). Minha definição nos ajuda a entender como qualquer comportamento pode se encaixar na cultura, de forma mais abrangente, ou não. As definições de matéria escura e cultura apresentadas aqui têm por objetivo promover uma base para a sobreposição (alguns diriam "compartilhamento") de comportamentos e conhecimentos etc., psicologia individual, e o papel do inconsciente individual na formação de uma cultura.

Esses conceitos também possibilitam uma noção de cultura que é fluida, projetada a partir da matéria escura dos indivíduos, em vez de nas sociedades per se. Essas noções de cultura e matéria escura também promovem hipóteses alternativas (EVERETT, 2016) para o nativismo baseado em conteúdo, e.g. Chomsky (1986); Pinker (1994); Barkow, Cosmides, e Tooby (1995).

\section{MEMÓRIA E CULTURA}

Meu primeiro exemplo do poder psicológico da cultura e sua relação causal com a cognição é retirado de pesquisa de campo realizada com outros cientistas cognitivos, com foco na memória de curto prazo. Esses pesquisadores e eu testamos a memória de curto prazo de caçadores-coletores da Amazônia (Pirahã), e comparamos os resultados com uma base de universitários estadunidenses. ${ }^{6}$ Envolvemos os Pirahã em duas tarefas, para testar sua memória de curto prazo (STM, FEDORENKO et. al., 2011, p. 4), examinando memórias de curto prazo fonológicas e espaciais. ${ }^{7}$ Para testar a primeira, avali-

5 Eles podem também nos ajudar a melhor situar e avaliar trabalhos importantes de ao menos dois dos principais programas de pesquisa - "Dual Inheritance Theory" (BOYD; RICHERSON, 1998) e "Cultural Attractor Theory" de Sperber e Hirschfield (2004). O primeiro é a ideia de que a cultura (de maneira quase idêntica ao chamado "Efeito Baldwin") pode levar a mudanças na evolução biológica, mesmo quando a evolução biológica endossa a cultura e a cognição. O segundo, para colocar em termos simples, é a ideia de que certos comportamentos e ideias acabam sendo mais disseminados e, portanto, mais bem-sucedidos do que outros.

6 Este experimento não foi nosso principal foco de pesquisa, mas simplesmente prolegômenos para exploração de outros aspectos da cognição Pirahã.

7 A língua Pirahã é parte da família linguística Mura. Tornou-se uma língua isolada, pois todas as outras línguas estão extintas. As vilas do povo estão localizadas às margens do rio Maici, tributário do Marmelos, que é tributário do Madeira, afluente do Amazonas, cerca de 800 milhas a sudoeste da cidade de Manaus, no estado brasileiro 
amos as habilidades dos Pirahã de lembrar blocos de fala sem sentido, uma aptidão importante para aquisição de língua(gem). Particularmente, pedimos que os Pirahã repetissem as sentenças cada vez mais longas de sílabas que não formavam unidades significativas. Alguns dos primeiros sujeitos tiveram dificuldade de lembrar as sentenças que pedimos para eles repetirem. Os resultados deles foram significativamente mais baixos do que os resultados do nosso grupo de controle. Isso nos surpreendeu. Consequentemente, reconsideramos o design da tarefa, apesar de ser a metodologia padronizada para testar a memória de curto prazo fonológica (STM). Organizamos as sílabas prosodicamente para que se assemelhassem às palavras em Pirahã, mesmo sem sentido. Os sujeitos, deparados com sequências de sílabas que tinham padrões de tom e acentuação apropriados, tiveram uma performance significantemente melhor, favoravelmente em relação ao nosso grupo de controle.

A memória de curto prazo fonológica se distingue, na literatura, da memória de curto prazo verbal, já que esta está reservada para lembrar blocos de materiais verbais significativos, como num teste span de dígitos ou teste span de palavras, que envolvem repetições de sentenças cada vez mais longas de dígitos ou palavras, respectivamente. Esses tipos de tarefas verbais são diferentes das tarefas de memória de curto prazo fonológicas (como span de sílabas ou repetição de pseudo-palavras) porque envolvem unidades significativas. O significado implica dependência no conhecimento de longo prazo, presumivelmente na forma de representações semânticas. Consequentemente, essas representações possibilitam uma variedade mais rica de estratégias "de blocos". Realizamos uma versão padrão do teste span de dígitos com participantes estadunidenses, a fim de avaliar o quanto nossa amostra era representativa da população geral em culturas industrializadas (essa tarefa não foi dada aos Pirahã).

Os participantes Pirahã foram testados individualmente em um cômodo pequeno por três pesquisadores. Daniel Everett forneceu as instruções a cada participante - o correspondente aproximado de "repita minhas palavras". (Como tenho amizade com os Pirahã, tendo convivido com eles por 30 anos, entre idas e vindas, a configuração experimental não intimidou nenhum pouco os participantes Pirahã, conforme, por exemplo, os vídeos das amostras dos experimentos relatados em Frank et al. [2008], disponível em http://tedlab.mit.edu/tedlab_website/Publications.html).

Os participantes acharam natural a tarefa de span de sílabas, e não tiveram dificuldade de entender as instruções. No entanto, para a tarefa de cubos de Corsi, quase todos os participantes pareceram ter dificuldades iniciais no entendimento de que a ordem serial era importante. Eles pareciam se concentrar em lembrar o conjunto de cubos tocados

do Amazonas. Quando comecei a trabalhar lá em 1977, a estimativa era de que havia aproximadamente 110 falantes. Hoje, estima-se que chega ao número de 1.000. 
pelo pesquisador, independentemente de ordem. Após vários experimentos de treinamento, nos quais um dos pesquisadores demonstrou uma sequência com span nível 2, e depois de outros dois pesquisadores repetirem a mesma sequência, a maioria dos Pirahã aparentaram ter entendido o objetivo da tarefa. Entretanto, manter a informação da ordem serial da tarefa de cubos de Corsi ainda foi difícil para os Pirahã. Devido a essa dificuldade, computamos um escore de span adicional para a tarefa de cubos de Corsi, na qual o intervalo do participante foi definido como o mais alto nível de span, no qual ele ou ela poderia repetir as duas sequências corretamente, não importando a ordem, com a adição de meio ponto, caso o participante conseguisse repetir uma das duas sequências corretamente, no próximo nível de span.

Por outro lado, a memória de curto prazo espacial, a habilidade de lembrar locais e sequências espaciais, é frequentemente avaliada por meio da tarefa de cubos de Corsi, originalmente desenvolvida como analógica não verbal dos testes verbais e fonológicos de memória de curto prazo. A tarefa de cubos de Corsi exige que os sujeitos se lembrem de sequências cada vez mais longas de batidas num conjunto de cubos dispostos num arranjo espacialmente aleatório.

É crucialmente importante observar, em relação à tarefa de memória espacial, que os Pirahã navegam tanto em terra como no rio, com bastante precisão. Suas rotinas exigem memórias espaciais intrincadas e vastas. De fato, dividiram mentalmente a selva e os rios à sua volta em áreas relativamente pequenas (nenhum estudo sistemático foi realizado), e conhecem cada uma das áreas pelo nome. Apesar de sua dependência regular na memória espacial, eles ainda assim tiveram uma performance significantemente abaixo do grupo de controle na tarefa de cubos de Corsi. ${ }^{8}$ Embora tenhamos modificado a metodologia e aperfeiçoado os resultados de memória de curto prazo fonológica, não fizemos isso com a tarefa de cubos de Corsi. No entanto, cada uma dessas tarefas é estranha para os Pirahã, ao passo que as duas são indiretamente familiares para os estudantes universitários estadunidenses (cuja cultura geralmente envolve uso de senhas para smart phones, códigos para uso de caixa eletrônico, e uma série de outros comportamentos de combinações de padrões visuais, estranhos à experiência dos Pirahã).

8 Para o teste de span de sílabas, criamos cinco sequências de sílabas consoante-vogal, cada duração de duas a oito sílabas. Para criar as sílabas, utilizamos todas as possíveis combinações das três vogais (i, a, u) e sete consoantes (p, b, t, k, g, h, e uma pausa glotal) na língua Pirahã (EVERETT, 1988). Todos esses fonemas estão presentes na língua inglesa, também. Portanto, as sílabas devem ser igualmente familiares para as duas populações. Certificamo-nos de que nenhuma sílaba ou combinações adjacentes de sílabas formassem palavras em Pirahã (segundo o conhecimento que Daniel Everett tem da língua) nem em inglês. Para a tarefa de cubos de Corsi, seguimos uma disposição de cubos utilizada em trabalho anterior (KESSELS et al., 2000). Criamos duas sequências de toques, cada duração entre dois e nove toques. Durante o teste, duas sequências adicionais no nível 2 de span foram criadas, para possibilitar mais experimentos de treinamento, com a duração mais curta para os participantes Pirahã" (FEDORENKO, et. al., 2011, 5ff). 
As diferenças de performance não se deram por conta da falta de entendimento das tarefas imediatas, conforme discutimos neste trabalho. Expliquei a tarefa a cada sujeito em sua língua (Pirahã). ${ }^{9}$ Cada um realizou a tarefa sozinho, com os outros sujeitos a uma distância da qual não podiam ser ouvidos.

Apesar de os Pirahã terem entendido as tarefas, para mim estava claro que eles não estavam "se identificando" com a performance necessária. Os nossos testes eram provenientes de algo fora da estrutura de conhecimento deles, de seus papéis sociais e valores. Isso foi sustentado quando a performance deles melhorou na tarefa da memória de curto prazo fonológica - fez mais sentido para eles, pois se encaixou melhor com as expectativas culturais deles.

Nossos resultados das diferenças na memória de curto prazo, com base nos diferentes contextos culturais, indicam para mim ao menos que as metodologias da ciência cognitiva são frequentemente vinculadas à cultura. Mas o que significa descrever algo como "vinculado à cultura"? O que é cultura, afinal? E como afeta, como consegue afetar, nossa cognição - nosso conhecimento, pensamento, e combinação deles? Reitero que esse é o propósito deste breve panorama. Há várias perguntas direcionadas para que consigamos atingir esse objetivo.

Logicamente não sou o único pesquisador nos últimos anos que chamou atenção para a cultura, no estudo da cognição. Stephen C. Levinson é outro, entre muitos outros, que argumenta a favor da importância da cultura no entendimento da cognição. As preocupações de Levinson estão resumidas em "The Original Sin of Cognitive Science" (LEVINSON, 2011), em que o autor oferece o seguinte anúncio de serviço público para cientistas cognitivos: entender a variação cognitiva é um pré-requisito para entender a cognição de maneira mais ampla. Os argumentos de Levinson foram confirmados, de maneira sólida, em muitos estudos ao longo dos anos, não apenas por meio de novas metodologias e campos de estudo, como a genômica através de imagens que ele discute, mas também pela velha pesquisa de campo, com a qual psicólogos, antropólogos, linguistas, filósofos, neurocientistas, e outros na ciência cognitiva, descobriram graus de variação intercultural na cognição, que de outra forma não seriam previstos.

Vários pesquisadores exploraram maneiras pelas quais histórias de vida se entrelaçam com a cultura na formação de habilidades cognitivas individuais, compartilhadas de maneiras interessantes pelas comunidades das quais fazem parte. Everett (2016) resume e expande muitas dessas pesquisas, valendo-se do trabalho de vários pensadores, tais como Michael Polanyi ("conhecimento tácito", Polanyi [2009[1966]; 1974]),

9 Os Pirahã são quase exclusivamente monolíngues. Quero dizer que ninguém na comunidade seria capaz de acompanhar uma conversa normal em outra língua que não fosse a sua, apesar de muitos homens saberem uma boa quantidade de substantivos e alguns verbos em português. 
Edward Hall (1973; 1976; 1990), e John Searle (1980a; 1980b; 1983; 1997). A matéria escura da mente é a combinação das apercepções individuais e da "cultura" (conforme definição anterior), o que imediatamente faz com que cada indivíduo seja único, e também parte de uma comunidade homogênea.

A fim de avaliar os efeitos profundos da cultura na cognição, a seguir analiso descobertas adicionais a respeito do papel da cultura na percepção, cognição numérica, gramática e cores. Também discuto como a cultura pode fornecer insights nas origens da língua(gem) e outros componentes das habilidades humanas, que tomamos por certos, como sendo ao mesmo tempo invariantes e únicos, para o Homo sapiens. Concluímos com algumas ideias para estudos adicionais.

\section{CULTURA E MATÉRIA ESCURA DA MENTE}

Conforme já vimos, a cultura é um conceito abstrato. Ela traz à tona uma gama de entendimentos e definições. Kuper (2000) discute sua variabilidade, controvérsia, e dificuldade de ser definida em detalhes. Alguns antropólogos chegam até a rejeitar a cultura como um construto útil para pesquisas antropológicas. Como já apontado anteriormente, um conceito "de verbo" sobre a cultura é mais atraente para muitos do que um conceito "de substantivo". Nesse sentido, as pessoas não "têm" cultura. Elas "fazem cultura". Porém, o que se faz ao fazer cultura? Segundo a definição apresentada anteriormente, a cultura e o fazer cultura engajam-se em três domínios cognitivos separados, amplos, mas integrados (Everett, 2016): estruturas de conhecimento, valores ranqueados violáveis, e papéis sociais multi-link. A língua(gem) e outros domínios também estão envolvidos, uma vez que são moldados por esses domínios mais amplos. Isso é crucial para entender a cultura como conceito dinâmico e para ir além das definições - que são relativamente vagas - oferecidas em estudos anteriores da cultura (se existem tais definições).

\section{DO ÉTICO AO ÊMICO}

O componente crucial do meu modelo para explicar os efeitos culturais na cognição e na formação da matéria escura é a emicização. Nossas apercepções, experiências pessoais, que nos marcam, de maneira consciente ou não, ocorrem dentro do nosso inconsciente emicamente formado, e são interpretadas por ele.

A emicização e a matéria escura representam, juntas, um processo de "desalienização". Todos nós nascemos estrangeiros (módulo que aprendemos no útero), e enfrentamos a tarefa de nos tornarmos nativos, por meio da emicização de nossas experiências, 
de forma que nossas interpretações, ações, e conjunto de comportamentos se encaixem na categoria esperada como "normal" pela sociedade na qual se dá o aprendizado - um processo de aprendizagem que, para mim ao menos, inclui a língua(gem).

Emicização é a noção de que o entendimento do mundo - inclusive a cognição, a lingua(gem), o comportamento de forma geral, etc. - é profundamente diferente para aqueles que estão dentro de uma cultura, os "nativos que fazem cultura" ou "falantes-nativos", do que para aqueles que estão fora do sistema. O termo é interpretado de forma diferente por alguns antropólogos, como no debate entre Pike e Harris (1990). Entretanto, para os propósitos deste trabalho, essas diferenças são ortogonais.

Quando caminho na selva com um homem Pirahã, por exemplo, um movimento suave num galho de árvore não me parece significativo. Não sei por que o galho está se mexendo. Tenho uma perspectiva ética da ecologia local. Porém, o homem Pirahã, tendo uma perspectiva êmica de seu ambiente, geralmente sabe se o movimento é um índice que sinaliza o vento, um macaco, um pássaro, ou outro objeto. As perspectivas êmicas moldam nossas língua(gens), culturas e cognição, a partir da interpretação da natureza, até a arte, ciência, e os processos de formação do nosso pensamento. ${ }^{10}$

Tendo feitos esses comentários iniciais, voltemo-nos a um exemplo do papel da cultura na percepção visual.

\section{A ANTROPOLOGIA DA PERCEPÇÃO}

A matéria escura e a cultura determinam não somente como interpretamos imagens, mas se conseguimos percebê-las ou não." $\mathrm{A}$ habilidade intercultural de interpretar fotografias é diretamente relevante para a ideia de que a cultura pode fornecer uma hermenêutica para interpretar o mundo. Além disso, um pouco de reflexão sugere que o diferencial da habilidade perceptual nesse sentido pode não ser inesperada. Afinal, no mundo natural, há poucas (se houver) experiências visuais bidimensionais, exceto talvez a partir de reflexos na água. Consequentemente, há um interesse especial em investigar culturas nas quais não há artes visuais bidimensionais, exposição a fotografia, ou alfabetização, uma vez que tais culturas poderiam nos fornecer informações sobre as origens da representação visual, particularmente se a percepção e a interpretação visual bidimensional são aprendidas culturalmente ou se são inatas.

\footnotetext{
10 O trabalho de Pike (1967) no qual essas ideias são desenvolvidas examina perspectivas êmica vs. ética de jogos de futebol americano, e uma grande variedade de outros comportamentos, tanto no âmbito público quanto no privado, por exemplo.

11 Muito desta seção foi retirado de Everett (2016, Cap. IV).
} 
Meu interesse nesse tópico teve início depois que notei que, quando mostrava aos Pirahã fotos deles mesmos e de outros na comunidade, eles olhavam fixamente para as fotos, e perguntavam-me de quê ou de quem se tratava certa foto, mesmo quando a foto retratava a própria pessoa ou um ente querido. Comentei o fato com alguns colegas, acreditando que isso se devia ao fato de que eles "não tinham tido muita experiência com fotos”. Alguns de meus colegas psicólogos consideraram que valia a pena acompanhar as observações, experimentalmente.

Antes de discutir nossos esforços para entender a interpretação de objetos bidimensionais, por parte dos Pirahã, devemos observar primeiramente que a dificuldade deles não é diferente do esforço dos ocidentais para entender representações de outros tipos, como na arte de forma geral, da moderna à impressionista, e à realista, uma vez que as representações, para serem interpretadas, necessitam encontrar um lugar na matriz cultural do observador. Susan Sontag (2013 [1973], p. 1) perspicazmente observa que "ao ensinar-nos um novo código visual, as fotografias alteram e expandem nossas noções do que vale a pena olhar e do que temos direito de observar. São uma gramática e, ainda mais importante, uma ética do ver". Também aponta que "finalmente, o resultado mais grandioso do empreendimento da fotografia é dar-nos o sentido de que podemos guardar o mundo todo em nossas cabeças - como uma antologia de imagens". O filósofo John Searle (1980A) também discute o papel da cultura na percepção de pinturas.

A argumentação técnica que se segue, com base na minha pesquisa de campo, foi retirada em grande parte de Yoon, Witthoft, Winawaer, Frank, Everett e Gibson (2014). A questão que me motiva é: "Nossa matéria escura - que se origina da cultura e da psicologia - ajuda ou atrapalha nossa habilidade de perceber o mundo em nossa volta?". A resposta curta é que são as duas coisas. Para entender mais claramente, primeiramente examino minhas próprias dificuldades em ver o que os povos da Amazônia veem. Depois, concentro-me nas dificuldades dos Pirahã em ver o que vejo.

Na época de chuvas, as trilhas da selva ficam inundadas. As cobras saem de suas tocas. Caimões avançam mais para a terra. Arraias, enguias e todos os tipos de criaturas podem ser encontradas em trilhas, que são secas e largas em épocas de seca. Nesse período, é difícil andar nessas trilhas, mesmo durante o dia, pois elas ficam cobertas de água, na altura do joelho, ou mesmo na altura do peito (tive que andar por horas, de vila a vila, nessas condições). À noite, essas trilhas são assustadoras. Quando ando com os Pirahã, geralmente estou de sapatos, e eles, descalços. Lembro-me de duas coisas que marcaram. A primeira é quase pisar num pequeno caimão (de três pés de comprimento). A segunda é quase pisar numa surucucu (cobra covinha). Nos dois casos, os Pirahã salvaram minha vida, ou ao menos um membro meu. Chocados pelo fato de que eu não conseguia detectar esses perigos óbvios, eles me puxavam na última hora, hora, alertando-me para prestar mais atenção onde pisava. Esses exemplos eram frequentes, durante as dé- 
cadas que passei com povos da Amazônia e mesoamericanos. E cada vez que acontecia, eles ficavam espantados pela minha aparente cegueira.

Dessa forma, desejo ressaltar que, mesmo quando exploramos limitações culturais da percepção dos Pirahã, há igualmente limitações culturais profundas nas percepções dos ocidentais (EVERETT, 2016). Em trabalho colaborativo, Mike Frank, Ted Gibson e eu realizamos vários experimentos entre os Pirahã em 2007 (desenhados e analisados com coautoria de YOON et. al. [2014]). Por fim, chegamos a várias conclusões, resumidas a seguir:

\begin{abstract}
Um princípio fundamental da ciência da visão é que a percepção não é simplesmente um reflexo passivo do mundo externo, mas sim um processo de interpretação construtiva de um input inerentemente ambíguo. Pensemos numa sombra projetada numa parede. A mesma siIhueta pode ser criada por diferentes objetos, de diferentes tamanhos, de diferentes distâncias do expectador. As imagens projetadas na retina têm a mesma ambiguidade inerente, e uma vasta gama de julgamentos perceptuais, que variam de acordo com a luz, com a cor, com a profundidade, com a forma e identidade, resultam de "inferências inconscientes" do sistema visual. Essas inferências são frequentemente presumidas como automáticas e culturalmente universais [...].
\end{abstract}

Conforme interpretamos o mundo à nossa volta, o problema não é ver os detalhes, mas sim reuni-los - costurando o que estamos vendo em perceptos coerentes ou "gestalt". Essa "junção" ocorre sem esforço e sem consciência. Nosso "ver" ético inicial se transforma, por meio da cultura, no perceber êmico, produzindo gestalt, nossa intepretação. ${ }^{12}$ Quando adequadamente emicizados, vemos melhor o todo - vemos coisas que não estão lá e não vemos coisas que estão. Consideremos como uma imagem corrompida poderia ser vista numa cultura sem experiência de visão bidimensional (conforme discussão detaIhada em YOON et. al. [2014]). As pessoas frequentemente deixam de reconhecer imagens de dois tons. No entanto, quando são mostradas as fotografias correspondentes, os dois tons se transformam num percepto coerente. Os sujeitos Pirahã estão usando conhecimento êmico para interpretar imagens éticas, ou simplesmente obtêm informações meIhores, desvinculadas do conhecimento interno ou externo? Os sujeitos que viam a jaguatirica em dois tons frequentemente cometiam erros de figura-fundo, atribuindo, incorretamente, algumas regiões de fundo para a figura, e algumas regiões de figura para o fundo. Reconfigurar as tarefas de figura-fundo, após olhar a fotografia, é "reorganizar" o agrupamento inicial de alguém, para atingir um estado perceptual diferente. Se o espec-

12 Esse processo de "juntar" uma interpretação de percepção crua foi primeiramente explicado detalhadamente por C. S. Peirce na metafísica, segundo a qual a percepção crua era uma "primeiridade" e a interpretação final era uma "terceiridade". Primeiridade, segundidade e terceridade aparecem ao longo da filosofia de Pierce e oferecem insights para vários aspectos da lógica e da cognição humana (EVERETT, no prelo, A). 
tador finalmente reconhece a imagem previamente não reconhecida, pode-se dizer que houve sucesso na reorganização das percepções. ${ }^{13}$

Uma questão importante que surge na presente discussão é se a reorganização perceptual, relatada por adultos, resulta da maturidade intelectual, em princípio comum em todas as culturas, ou se resulta da matéria escura adquirida em contextos culturais específicos (e histórias individuais particulares). Os Pirahã adultos têm pouca experiência ou conhecimento da transformação visual que conecta uma foto e uma imagem de dois tons. Por outro lado, eles possuem sistemas visuais fisiologicamente maduros, e experiências de vida com tarefas visuais complexas, tais como caça e pesca.

Concluímos que tanto os Pirahã quanto os participantes do grupo de controle dos Estados Unidos apontaram, com precisão, as posições-alvo em nossas representações em 2-D (sempre pedimos a eles que apontem para um olho ou uma pessoa) das imagens que não são de dois tons, sem ver as fotos correspondentes de forma nítida (nosso grupo de controle com $100 \%$ de precisão e os sujeitos Pirahã com 88,9\% de precisão), mostrando que os participantes entenderam a tarefa. Os participantes estadunidenses localizaram os alvos, com sucesso, nas imagens de dois tons, sem uma foto nítida correspondente, com um índice de sucesso de $72,5 \%$. Para os Pirahã, a percentagem de acertos foi bem menor (22,5\% dos testes). Os sujeitos do grupo de controle identificaram os alvos em fotos nítidas, inalteradas, $100 \%$ do tempo, enquanto que os Pirahã tiveram uma taxa de precisão de 90,3\%. Todos os participantes Pirahã indicaram o alvo corretamente em pelo menos sete das dez fotos. Os dados dos testes, nos quais os Pirahã não reconheceram a foto corretamente, foram excluídos de análises subsequentes.

Testamos se os Pirahã eram capazes de reorganizar, de maneira perceptual, as imagens de dois tons, quando estavam olhando essas imagens com as fotos originais (sem

13 "Na esteira da escola de Gestalt, utilizamos os termos "organização perceptual" e "reorganização perceptual", para enfatizar o processo pelo qual características de imagens locais são adequadamente integradas ('agrupadas') ou segregadas, a fim de atingir uma interpretação significativa da imagem - um 'gestalt'(KOHLER, 1929)". 
photoshop). A performance dos participantes estadunidenses foi quase perfeita. Porém, os Pirahã tiveram dificuldades. A diferença foi marcante. ${ }^{14}$

A questão para a qual devemos olhar é por que essa tarefa de reconhecimento e reorganização perceptual foi tão mais difícil para os Pirahã. Há algumas possíveis explicações para nossos resultados. Podemos descartar a explicação de que os Pirahã talvez não tivessem compreendido a tarefa. Outra explicação é a familiaridade dos Pirahã com os estímulos que tinham que avaliar, e a dificuldade da tarefa. De certa forma, esse é o ponto, mas pareceu que não houve mal-entendidos em relação ao que eles estavam tentando fazer, e nem com o tratamento ou o propósito dos estímulos - eles receberam coisas para descrever. Após decidirem o que era que estávamos observando, a próxima tarefa foi considerar a gama de possíveis diferenças na percepção e discutir possíveis fontes conceituais ou experienciais de diferenças, na reorganização perceptual dos grupos.

Constatamos que os adultos estadunidenses tiveram precisão em detectar a correspondência entre as fotos e as imagens correspondentes de dois tons, com photoshop,

14 A metodologia foi empregada da seguinte forma:

"Os participantes incluíram membros adultos da tribo Pirahã ( $N=9$, média de idade estimada $=30$ anos) e, como grupo de controle testado com os mesmos estímulos, universitários de Stanford University, corpo docente e quadro de funcionários ( $\mathrm{N}=8$, média de idade $=26$ anos). Uma tarefa controle adicional com estímulos adicionais foi testada com os alunos de Stanford ( $N=10$, média de idade $=19$ anos). A acuidade visual da população Pirahã foi testada por Daniel Everett e outros, alguns anos antes, como parte de uma triagem básica para serviços médicos: a população estava, em geral, normal, sem catarata e uma pequena incidência de miopia. Dez imagens de dois tons foram criadas no PhotoShop com embaçamento e posterização (reduzindo o número de valores de escala distintos - cinza - para dois, neste caso: preto e branco) fotografias em tons de cinza de animais e de pessoas encontradas no ambiente cotidiano dos participantes Pirahã. A quantidade de embaçamento e os pontos limiares preto/branco foram estabelecidos de forma independente, para cada fotografia, com base no procedimento repetido de tentativa e erro até ficarmos satisfeitos com as impressões subjetivas de que os dois tons (A) eram difíceis de reconhecer, sem ver antes a fotografia da qual eles foram derivados ("sem uma dica"), e (B) fáceis de ver após olhar para a fotografia ("com uma dica"). Essa criação e seleção do estímulo foram conduzidas pelo julgamento perceptual dos pesquisadores. As imagens foram impressas em cartões de $12 \times 12 \mathrm{~cm}$. Outros dois pares de imagem foram criados, que não incluíram dois tons. Nesse caso a correspondência foi mais fácil de ver. Serviram como itens preparatórios, e também para ter certeza de que os participantes entendiam a tarefa".

"Cada experimento teve três estágios. No estágio 1, foi apresentada aos participantes uma imagem de dois tons. Foi pedido a eles que indicassem o que reconheciam, apontando para o olho ou para a pessoa Pirahã na figura. As respostas foram marcadas com um adesivo nas localizações indicadas. Experimentos nos quais o alvo não foi inicialmente identificado foram considerados "experimentos de reorganização do candidato". Esses experimentos foram particularmente interessantes, uma vez que permitiram verificar se uma imagem de dois tons, não reconhecida inicialmente, poderia ser reinterpretada com sucesso depois que a fotografia correspondente fosse vista. Esses experimentos continuaram com os estágios 2 e 3 . No estágio 2, foi mostrada aos participantes somente a fotografia correspondente, e foi solicitado a eles que apontassem para o olho ou para a pessoa Pirahã. No estágio 3, a imagem de dois tons e a fotografia foram mostradas, lado a lado. O pesquisador então apontou várias vezes para as duas imagens, utilizando a palavra em Pirahã para "a mesma", para transmitir a correspondência entre a foto e a imagem de dois tons. Logo após, foi solicitado ao sujeito que apontasse novamente para o olho ou para a pessoa na imagem de dois tons."

"Além disso, testamos os alunos de Stanford com uma tarefa de manipulação de alinhamento. Essa tarefa controlou a possibilidade de que a performance dos participantes estadunidenses não foi devida ao reconhecimento das imagens de dois tons. Foi meramente localizar o ponto no cartão de dois tons, na mesma localização do ponto correspondente na fotografia". 
mesmo quando as imagens não mais apresentavam uma estrutura coordenada previsível, uma em relação à outra. Isso significa que os adultos estadunidenses têm que usar a compreensão êmica do conceito das representações bidimensionais, reorganização perceptual, a fim de identificar a localização deslocada de modo imprevisível, na imagem de dois tons, na figura. Consideramos as diferenças na performance dos estadunidenses e dos Pirahã em termos de "letramento perceptual", atribuindo essas diferenças às diferenças culturais, em estudos e treinamentos com materiais simbólicos visuais.

Além disso, uma vez que as fotografias que usamos foram de pessoas e animais conhecidos pelos Pirahã, é improvável que o resultado se dê devido à falta de familiaridade com os itens retratados. De fato, os Pirahã conheciam os itens, a fauna e as pessoas, meIhor do que os sujeitos estadunidenses do grupo de controle.

A falta de habilidade dos Pirahã nas tarefas bidimensionais, como a minha em ver animais perigosos na floresta etc., simplesmente demonstra que um sistema visual maduro é insuficiente para garantir reconhecimento do que se vê. O sistema maduro "vê" o ético apenas até o ponto que passou por emicização em uma cultura específica, com suas experiências particulares, expectativas, etc.

Novamente, esses experimentos não demonstram apenas a relevância da cultura para a percepção, mas também corroboram as noções de Peirce a respeito de primeiridade, secundidade e terceiridade. A primeiridade nesse caso é a percepção crua - uma sensação de algo à minha frente. A secundidade é uma visão do que esse algo é. A terceiridade é uma generalização que relaciona uma percepção às outras, além do estímulo presente (como ver algo vermelho, reconhecer que esse algo é vermelho, e então vê-lo como um exemplo da cor vermelha, segundo Everett, no prelo).

Uma questão que vem à tona, que é enfatizada por um dos avaliadores deste trabaIho, é como a cultura se relaciona com a exposição e efeitos de familiaridade, de maneira mais geral. Segundo estudos cognitivos de envelhecimento, realizados nos Estados Unidos, alguns idosos talvez precisem de mais prática e exposição a computadores, teclados etc., do que pessoas mais jovens. Questões semelhantes vêm à tona com a maioria das diferenças em áreas especializadas, tais como efeitos melhorados de memória operacional para profissões diferentes, como taxistas, garçonetes e jogadores de xadrez, por exemplo. A resposta no meu modelo é que, quando mudamos de uma perspectiva ética (como acabar de aprender a ser taxista) para a perspectiva êmica de um taxista experiente, passamos pela desalienazação, e entramos numa subcultura com novas estruturas de conhecimento, valores ranqueados e papéis sociais. Assim, profissões são, de fato, (sub)culturas da cultura estadunidense mais ampla, e considerações similares a essas acima descritas são aplicáveis para os caçadores-coletores da Amazônia. 


\section{A ANTROPOLOGIA DE NÚMEROS E COGNIÇÃO NUMÉRICA}

Outra observação que fiz há anos (EVERETT, 2005, 2008, 2012, 2016) foi que os Pirahã não têm palavras para números, e nem conceito de contagem. Assim como fiz com todos os outros comentários controversos de minha pesquisa de campo, solicitei ajuda para testes rigorosos do vocabulário de números em Pirahã, e sua cognição numérica.

Após terminar nossa pesquisa com números e cognição numérica, Mike Frank, Ted Gibson, Evelina Fedorenko e eu (FRANK et. al., 2008) questionamos se falar uma língua sem palavras para números poderia mudar a maneira pela qual falantes percebem quantidades exatas. Essa também foi a perspectiva de um trabalho anterior de Peter Gordon (2004) sobre os Pirahã. Demonstramos, em nosso último estudo, que os Pirahã não têm nenhum método linguístico para expressar quantidades exatas, nem mesmo "um". Entretanto, quando era pedido que eles realizassem tarefas de emparelhamento (diferentemente da performance constatada por Gordon, conforme Everett e Madora, 2012), os falantes de Pirahã foram capazes de realizar emparelhamentos exatos com um grande número de objetos, com perfeição, mas não conseguiram realizar tarefas de emparelhamento envolvendo memória. Esses resultados sugerem que a língua(gem) para números exatos é uma invenção cultural, e não uma universalidade linguística. Numerais são uma tecnologia cognitiva para acompanhar a cardinalidade de grandes conjuntos ao longo do tempo, espaço, e mudanças na modalidade. Devo acrescentar que essa tecnologia é inventada, emprestada, ou implementada, se satisfizer uma necessidade cultural mais ampla.

Esta pesquisa é crucial para o entendimento de que os números são ferramentas, não dons biológicos. Everett (2017) corrobora essa visão no estudo de números e cognição numérica, e seus efeitos, de forma intercultural e interlinguística.

Outros trabalhos como os de Wnuk e Maiid (2014), e Gibson, et. al. (2017), demonstram o papel da cultura na percepção de cores e no olfato, o que não esgota os estudos. ${ }^{15}$

\footnotetext{
15 Em correspondência pessoal, o principal pesquisador de campo da cultura Maniq, Helmut Lukacs, contestou veementemente as alegações de Wnuk e Majid. Estou preparando um trabalho de avaliação dessas alegações, a partir das anotações de campo de Lukacs.
} 


\section{EFEITOS CULTURAIS NAS GRAMÁTICAS}

\subsection{FONOLOGIA}

Apesar de eu ter discutido esses dados em outros trabalhos (EVERETT, 1979; 1985; 2008), vale revisá-los aqui para finalizar nossa apresentação dos efeitos da cultura na gramática, de forma mais geral. Conforme apontado em Everett (1979; 1982; 1985), a fonologia Pirahã não pode ser descrita nem entendida completamente sem conhecimento de sua interação com a cultura. A seguir apresento os motivos para tal pensamento.

Imaginemos que uma língua possa ter vários sistemas/várias modalidades de estrutura de sons, além de sua fonética e fonologia. Consideremos então a possibilidade de que as modalidades podem afetar umas às outras, mas não necessariamente por meio de regras ou hierarquias de restrições, recursos padrão da própria teoria fonológica. Se for assim, para entender o sistema de sons de uma língua, L, em qualquer nível (por exemplo, 'o que acontece' ou 'o que falantes nativos sabem quando conhecem o sistema de sons de sua língua'), é preciso analisar cuidadosamente as modalidades de expressão disponibilizadas por meio da etnografia da comunicação, não meramente por meio de um aparato formal supostamente universal. Corolários desse contexto podem incluir, por exemplo, o surgimento de novos papéis para velhas restrições (restrições de fidelidade de segmentos no nível alto da hierarquia para marcar tipos silábicos; as sílabas são mantidas, uma forma de fidelidade prosódica, a fim de analisar sequências de fala mais longas, não meramente para melhorar a percepção dos segmentos; e assim os argumentos a favor das sílabas pode ir além da fonotática e segmentais melhores, e a sílaba pode exercer papéis não previstos pela chamada 'hierarquia fonológica'). Se isso fosse verdade, um campo de trabalho coerente (EVERETT, 2004) evoluiria a partir de uma curiosidade ou desiderato para um imperativo. Existe caso assim? Certamente. Consideremos os seguintes fatos sobre a fonologia Pirahã, começando pelos fonemas.

\section{Fonemas em Pirahã}

Consoantes ()$=$ ausentes na fala das mulheres

$\begin{array}{lll}\mathrm{p} & \mathrm{t} & \mathrm{k} \\ \mathrm{b} & \mathrm{g}\end{array}$

(s) k ?

$\mathrm{h}$

Vogais

i

a

0

O inventário segmental em Pirahã é um dos menores do mundo (a única língua com um inventário menor é Rotokas, que não tem tons). Vale a pena observar que /s/ está nos 
()s porque não aparece na fala das mulheres, mas só na dos homens (as mulheres usam /h/ nos casos em que os homens usam /s/e /h/).

Apesar de ser este um dos mais simples inventários fonêmicos segmentais do mundo (o inventário das mulheres parece ser o mais simples que se conhece), devemos justapor, a essa simplicidade, a complexidade da prosódia Pirahã. A regra de acentuação em Pirahã é um bom começo, já que é bem conhecida.

Essa regra (EVERETT \& EVERETT, 1984) é considerada uma das mais complexas e incomuns regras de acentuação na literatura, principalmente por suas consequências fonológicas (em vez de, por exemplo, qualquer dificuldade em dizê-la ou reconhecê-la):

Regra de acentuação em Pirahã: Acentua-se o "token" mais para a direita do tipo silábico mais pesado, nas últimas três sílabas da palavra.

A base fonética de 'peso' em (1) é apenas assim: As consoantes surdas são sempre mais longas do que as consoantes sonoras. Há cinco pesos silábicos baseados parcialmente nesse contraste:

Os cinco pesos silábicos em Pirahã: CVV>GVV>VV>CV>GV ("C" = consoante surda e "G" = consoante sonora)

Além disso, Pirahã é uma língua tonal. No entanto, a acentuação, o tom e o peso da sílaba variam, de forma independentemente, na língua(gem). Para ver isso, revisarei uma série de exemplos simples abaixo. Nesses exemplos, o tom independe da acentuação. ' = tom alto; sem acento na vogal = tom baixo. A sílaba acentuada é marcada por !. Não há acentos secundários.

$\begin{array}{ll}\text { (1) a. !tígí } & \text { 'small parrot' } \\ \text { b. !pigi } & \text { 'swift' } \\ \text { c. !sabí } & \text { 'mean, wild' } \\ \text { d. !rábi } & \text { 'to stay' } \\ \text { e. tí!'híi } & \text { 'bamboo' } \\ \text { f. ri!ti } & \text { 'forehead' } \\ \text { g. ti!ní } & \text { 'honey bee' } \\ \text { h. tí!hì } & \text { 'tobacco' }\end{array}$

Por conseguinte, ao lado da fonologia segmental extremamente simples do Pirahã, há uma rica gama de prosódias. Isso nos leva a questionar se a língua explora esse diferencial de complexidade de alguma forma. De fato, segundo Everett (1985), a comunicação em Pirahã faz uso crucial dos CANAIS em (4), abaixo. Hymes (1974) define um canal como "meio físico sociolinguisticamente restrito, utilizado para levar a mensagem da fonte até o receptor". As quatro principais modalidades ou canais em Pirahã, depois da fala "normal", são: 
CANAL

a. FALA CANTAROLADA

b. FALA GRITADA

c. FALA MUSicAL ('big jaw')

d. FALA EM ASSOBIO
FUNÇÕES

Disfarce

Privacidade

Intimidade

Falar de boca cheia

Comunicação entre criança e babá

Longa distância

Dias chuvosos

Uso mais frequente - entre cabanas e

cruzando rios

Novas informações

Comunicações com entidades

espirituais

Danças, flertes

As mulheres produzem isso

quando estão ensinando Pirahã

com mais naturalidade do que

homens. A fala musical das mulheres

mostra separação muito maior

de tons

al tos e baixos, e maior volume.

('azedo' ou 'boca após beijo' Caça - mesma

raiz que 'beijar' ou formato da boca

Apenas homens - após comer limão)

Melodia não usual, utilizada para atividades

lúdico-agressivas

O exemplo abaixo ilustra como as informações prosódicas em Pirahã são exploradas para criar esses canais. O inventário acima demonstra em parte como os segmen- 
tos contribuem pouco para o conjunto total de informações fonológicas numa determinada palavra em Pirahã. Percebemos que a frase 'There is a paca there' tem uma representação tonal quase musical (na qual um acento agudo numa vogal representa um tom alto, e nenhum acento na vogal significa que a vogal tem bom baixo), base para os canais resumidos acima.

\section{(2) kái?ihí?ao -Paagá gáihí paca -poss/exist-be there 'There is a paca there.'}

Todos os canais devem incluir as informações prosódicas completas (acentuação, tom, duração, entonação), embora somente o canal da consoante e da vogal precise incluir as vogais e as consoantes.

Na forma musical, há um tom decrescente, seguido por um tom curto baixo, com uma anterior quebra no assobio (em que a pausa glotal, ?, teria estado em kai?ihi), seguido por outra quebra curta (onde estaria o h) e um tom alto curto, e assim por diante. Assim, as fronteiras silábicas estão claramente presentes nos canais do assobio (cantalorar e gritar), embora os próprios segmentos não estejam presentes. A sílaba, nesse caso, indica a duração, oferece um contexto abstrato para colocação do tom, a palavra em geral é acentuada de acordo com o peso silábico (detalhes em EVERETT, 1988). A sílaba nesses casos é vital para a comunicação na diferenciação de canais, principalmente na análise do input.

Será que a descoberta de canais assim implica relação causal entre a cultura e a gramática? Esses canais devem ser tratados como parte da gramática ou não? Observemos que esses canais dependem crucialmente dos pesos silábicos e da regra de acentuação mencionados acima. Seja como for, eles ajudam a representar o que de outro modo seria um nível anômalo de complexidade na regra da acentuação. No entanto, os fatos vão além disso. Consideremos o seguinte exemplo do que Everett (1985) chama de efeito de fonema 'sloppy'

(3) tí píai kí píai kí kíai pí píai Rí píai Rí /íai tí píai, etc. ("tí tíai, * gí gíai, "bí bíai) 'me too' (4) ?apapaí kapapaí papapaí ?a?a?aí kakakaí ("tapapaí, " tatataí, " bababaí, " gagagaí) 'head

?ísiihoái kísiihoái písiihoái píhiihoái kíhiihoái 'liquid fuel 16

Pirahã permite uma grande quantidade de variação entre consoantes, embora não para as características [contínuo] ou [voz]. Isso pode ser considerado, mas somente se 
nos referimos aos canais do Pirahã. Os exemplos não gramaticais acima demonstram que as características [contínuo] e [voz] estão conectadas, no sentido de que talvez nunca variem no efeito. Somente as características de lugar podem variar. Sem referência aos canais, não há explicação para isso. À luz dos canais, isso se sucede porque [contínuo] e [voz] são necessários para a colocação dos acentos (EVERETT, 1988), que, por sua vez, deve ser preservada para cada canal do discurso, ou a restrição abaixo é violada:

Restrição na carga funcional e contraste necessário (EVERETT, 1985):

(4) a. Maior dependência no canal ${ }^{\circledR}$ Mais necessidade de contraste

b. Menor dependência no canal ${ }^{\circledR}$ Menos necessidade de contraste

Não estou alegando que a ausência da variação para diferentes valores do [contínuo] é prevista somente pelos 'canais'. Esse caso de fato exige que investiguemos mais a conexão entre [contínuo] [voz]. Não há alegação de que a etnografia substitui a fonologia! Porém, alego que, sem o estudo dos canais e de seu papel na cultura Pirahã, até mesmo entender a fonologia segmental do Pirahã é impossível.

A lição para o pesquisador de campo e para o linguista teórico a ser tirada desses exemplos é apenas a seguinte: primeiramente, a língua(gem) e a cultura devem ser estudadas juntas; em segundo lugar, como canal dependente da modalidade, a fonologia deve estar sujeita a restrições que são (I) específicas da língua e (II) fundamentadas não somente nas propriedades físicas da instanciação da modalidade (fonética), mas também, ou alternativamente, nos canais específicos da cultura, em relação ao discurso empregado.. Este é um resultado importante, pois demonstra que as 'condições da interface' do SISTEMA COMPUTACIONAL HUMANO, segundo os termos de Chomsky (1995), podem variar além da PF e LF, se definimos um sistema de interface como um sistema que estabelece limites na interpretabilidade para $\mathrm{HC}_{\llcorner}$. Tais exemplos também mostram como o campo de trabalho coerente pode ser útil para a teoria. Consequentemente, não somente o pesquisador de campo, como também o fonólogo, podem engajar a língua(gem) como formadora de um todo coerente com a cultura. Isso acarreta um campo de trabalho mais culturalmente informado.

\subsection{MORFOSSINTAXE}

Até aqui, os fatos relatados podem ter sido surpreendentes, mas não muito controversos. Entretanto, quando nos voltamos para examinar os efeitos culturais na gramática, vamos contra uma corrente principal de pensamento que nega essa possibilidade a priori. Não analisarei a controvérsia sobre a cultura e a gramática Pirahã aqui. Concentro- 
me nos fatos. Não sou o primeiro pesquisador a sugerir que culturas afetam as gramáticas. Na teoria conhecida como "Gramática Cognitiva", isso é vital: "Teorias linguísticas cognitivas reconhecem o conhecimento cultural como base, não só do léxico, mas como facetas centrais da gramática também" (LANGACKER, 1994, p. 31). Por outro lado, Edward Sapir apontou, em sua monografia de 1921, Language, que línguas distintas podem compartilhar uma única cultura (como tem sido o caso, até certo ponto, com a civilização ocidental, durante séculos). Portanto, culturas e línguas não podem sempre ser relacionadas com facilidade. Em meu livro Language: The Cultural Tool(EVERETT, 2012), argumento que, embora gramáticas e culturas sejam distintas, e, embora talvez sigam cursos históricos semi-independentes, elas se entrecruzam de maneiras muito mais profundas do que pensam frequentemente linguistas, principalmente linguistas formais. $O$ campo todo da antropologia linguística, afinal, é dedicado ao exame das várias formas de interação entre a cultura e a língua(gem), inclusive a gramática.

Olhemos um exemplo da Nova Guiné, primeiramente. John Roberts, na gramática da língua amele da Nova Guiné, discute como e por que a expressão do predicado 'to give' não utiliza verbo, e trata os morfemas de concordância verbal como tipos de predicados, a fim de comunicar a imediatidade cultural "de base experiencial" (NEWMAN, 2002, p. 79) do verbo to give nessa língua (esse tipo de análise é facilitado em teorias com bases mais funcionais ou semânticas, como Role and Reference Grammar [EVERETT, 2016]):

(5)

$$
\begin{aligned}
& \text { a. Naus Dege ho ut } \text {-en. } \\
& \text { Naus Dege pig 3sG.IO -3sG.SUBJ.PAST } \\
& \text { 'Naus gave Dege the pig.' (Roberts 1987, p. 34) } \\
& \text { b. lia dana leis sab al -ig -a. } \\
& \text { I 'Igave the two men food.' (ROBERTS, 1987, p. 316) }
\end{aligned}
$$

Não há verbo "to give" em amele. Há somente elementos pronominais de concordância, em orações a respeito de "dar". Entretanto, para outras expressões, são necessários verbos:

$\begin{array}{llllll}\text { (6) Jo eu ihac } & -\mathrm{i} & -\mathrm{ad} & \text {-ig } & \text {-en. } \\ \text { house that show PRED } & -2 \mathrm{PL.IO} & \text { 1sG.suBJ } & \text { - FUT } & \\ \text { '/ will show that house to you (plural).' (ROBERTS, 1987, p. 69) } & \end{array}$

Isso é diferente de línguas com verbos explícitos para "to give", já que se alega que a base experiencial de dar na cultura amele favorece a derivação semântica a partir da inversão dos elementos pronominais, marcando objetos diretos e indiretos e, simultaneamente, com nenhuma marca no verbo.

Wierzbicka $(1992,1997,2014)$ fornece exemplos de restrições culturais na gramática em russo. A autora mostra como a "palavra-chave" sud"ba ("destino"), por exemplo, designa uma maneira russa de perceber a vida, manifestando-se no léxico russo, estrutura fra- 
sal, e morfossintaxe (detalhes em GODDARD, 2002). Segundo Cliff Goddard (2002, p. 55), a etnosintaxe é codificar uma "etnofilosofia particular" na própria gramática (como nos exemplos em WIERZBICKA e ROBERTS). Também aceito essa conceptualização.

Além disso, argumentei (EVERETT, 2008) a favor de uma "palavra-chave" similar, codificando um valor cultural chave em Pirahã. A palavra é xibipiio, que indica liminaridade experiencial (i.e., algo que acabou de sair ou está saindo, ou algo que acabou de entrar ou está entrando, em uma percepção visual ou auditiva de alguém). Everett (2005) descreve uma gama de características incomuns da cultura e linguagem Pirahã, muitas das quais nunca foram documentadas para outras línguas (se bem que não nos surpreenderíamos se muitas outras línguas tivessem características similares, ou se Ihes faltassem tais características). Tais características incluem: o mais simples sistema de parentesco conhecido, falta de palavras para cores, falta de números e contagens, ausência de tempos perfeitos, ausência de mitos de criação, ausência de mitos históricos ou ficcionais, ser monolíngue após mais de trezentos anos de contato constante com brasileiros, e ausência de recursividade (contra HAUSER, CHOMSKY, E FITCH, 2002). Propus explicar todos esses fatos em Immediacy of EXPERIEnce Principle, IEP (Princípio da Imediatidade da Experiência). Esse é um princípio encontrado, com certa persistência, em muitas línguas amazônicas (em GONÇALVES, 2005, há uma discussão da presença da Imediatidade da Experiência como um valor cultural em toda a Amazônia.)

Os efeitos da matéria escura são abrangentes. De fato, o IEP afeta profundamente a gramática Pirahã. Para ver como, comecemos com a reiteração desse princípio:

Princípio da Imediatidade da Experiência (IEP): os enunciados declarativos em Pirahã contêm somente afirmações relacionadas diretamente com o momento da fala, ou experienciadas (i.e. vistas, ouvidas, deduzidas, etc. - conforme a gama de evidenciais em Pirahã, conforme Everett (1986, p. 289) pelo falante ou testemunhadas por alguém que vivia na mesma época do falante).

Everett (2005) oferece uma série de argumentos a favor da IEP, com base nos pontos empíricos mencionados anteriormente, e também (entre outras coisas) a noção culturalmente importante de 'liminaridade experiencial' xibipíío, conforme Everett (2008). Essa palavra é mais uma evidência da liminaridade como conceito cultural e individual em $\mathrm{Pi}$ rahã. É utilizada para descrever coisas que entram e saem do campo da visão ou da audição, desde a fagulha de um fósforo até o desaparecimento ou aparecimento de uma canoa na curva de um rio.

Passando dessa afirmação cultural inicial para a gramática (e depois conectá-las), a evidência de que falta recursividade em Pirahã, também discutido em Everett (2012a) se dá conforme segue (PERFORS et. al. [2010] têm outro tipo de abordagem para verificar as gramáticas das línguas):

Primeiramente, a falta de recursividade corretamente prevê que verbos factivos e epistêmicos estarão ausentes. Isso acontece porque, se falta recursividade em Pirahã, 
não há então maneira para expressar verbos factivos como verbos independentes, já que isso exigiria uma oração completiva. Por usa vez, isso necessitaria encaixes e, portanto, ceteris paribus (em algumas análises), uma regra recursiva na sintaxe Pirahã. Pirahã expressa tais noções por meio de sufixos verbais, consistentes com a hipótese de 'não haver recursividade', não com orações completivas.

Em segundo lugar, em Pirahã não há marcadores de subordinação. Isso é também previsto em minha hipótese, uma vez que, se não há recursividade em Pirahã, não há subordinação a marcar.

Em terceiro lugar, Pirahã não tem partículas de coordenação disjuntiva (e.g. 'or). A ausência de marcadores explícitos disjuntivos é prevista em minha hipótese, pois sua presença implica recursividade.

Em quarto lugar, Pirahã não tem partícula de coordenação conjuntiva (e.g. 'and'). Há somente uma partícula mais geral, píaii, que pode aparecer antes do verbo ou no final da oração, e que significa 'é portanto/simultâneo' (significado vago). Essa partícula nunca funciona como uma conjunção propriamente. Somente fornece a informação de que essas duas coisas foram simultâneas. Novamente, isso é previsto em minha análise, já que a coordenação também implica recursividade.

Em quinto lugar, Pirahã não tem orações completivas sintáticas. Se Pirahã tem recursividade, onde estão os dados inequívocos? ${ }^{17}$ Defendi que não há orações encaixadas. Outros defendem, com base nos meus próprios dados e minhas análises anteriores, que há. (NEVINS; PESETSKY; RODRIGUES, 2009). ${ }^{18}$ Porém, apesar de os quotativos poderem ser encaixados, não há níveis múltiplos de encaixes, que seriam esperados se $\mathrm{Pi}$ rahã tivesse recursividade.

Em sexto lugar, Pirahã não possibilita recursividade de possessivo. O que apontei sobre os possessivos em Pirahã não é simplesmente que lhe falta recursividade de possui-

17 Em um novo volume (AMARAL et. al., 2018), Sauerland e vários autores criticam minhas análises do Pirahã, com base em dados supostamente novos. No entanto, como apontei em Everett (no prelo, b), essas críticas são baseadas numa combinação de dados questionáveis (uma vez que nenhum dos críticos fala Pirahã e nem tiveram nenhum acesso, portanto, a falantes nativos) e uma concepção errônea, a partir da incapacidade de teoria de Chomsky de levar em conta fenômenos sintáticos intersentenciais, ao contrário da sintaxe intrasentencial. Mais especificamente, Saverland alega que as condições de verdade que emergem de seus experimentos demonstram a existência de orações encaixadas em Pirahã. Dois outros têm a ver com "auto-encaixes" em locuções nominais e locuções prepositivas. Porém apesar de esse livro ser novo, essas alegações não são novas. Eu já as respondi detalhadamente. Em Everett (no prelo, b), Everett 2016 (http://ling.auf.net/lingbuzz/002857), trato de por que a semântica não pode diagnosticar a sintaxe e por que as condições de verdade não dependem de encaixes. Em Everett (2017 https://daneverettbooks.com/a-discussion-of-understanding-recursion-and-looking-forself-embedding-in-Pirahã/) discuto as alegações de que haja estruturas com "auto-encaixes" em Pirahã.

18 Conforme apontei, o trabalho de Nevins, Pesetsky, e Rodrigues (2009) é baseado em minhas análises e dados anteriores. Responder a um trabalho anterior meu é como ter um debate comigo mesmo - o Dan Everett de 30 anos de experiência de campo entre os Pirahãs vs. o Dan Everett de 14 meses de experiência de campo, escrevendo uma tese. 
dor pré-nominal, mas que falta recursividade de possuidores em qualquer lugar na locução nominal. Nevins, Pesetsky e Rodrigues (2009) talvez tenham razão ao sugerir que o alemão, como o Pirahã, não tem recursividade de possuidor pré-nominal. Porém, o alemão tem recursividade de possuidor pós-nominal, ao passo que Pirahã não tem nenhum. Isso é contemplado em minha análise.

Em sétimo lugar, Pirahã proíbe modificações múltiplas numa mesma frase. Conforme discuto acima e em Everett (2008) e (2009), pode haver no máximo um modificador por palavra. Não se pode dizer em Pirahã 'many big dirty Brazil-nuts'. Seria preciso dizer 'There are big Brazil-nuts. There are many. They are dirty'. Essa estratégia paratática é contemplada em minha análise, pois adjetivos múltiplos, como em inglês, implicariam recursividade. A estratégia paratática não implica recursividade.

Em oitavo lugar, em Pirahã a semântica não demonstra escopo de uma oração em outra, e.g., não há "Neg-raising". Em Pirahã faltam exemplos como 'John does not believe you left' (em que 'not'pode negar 'believe' ou 'left', como em 'It is not the case that John believes that you left' vs. 'It is the case that John believes that you did not leave'). Nesse exemplo 'not'pode ter escopo sobre 'believe'ou 'left'. Isso não é possível sem recursividade. Então minha análise prevê a ausência dessas relações de escopo. Também está contemplado, corretamente em meus relatos, que isso é impossível em Pirahã, já que implicaria recursividade.

Em nono lugar, Pirahã não apresenta LDD (long distance dependencies), exceto entre orações independentes, i.e, discurso. Os tipos de exemplos que são tipicamente apresentados para LDD incluem:

'Who do you think John believes _-_ (that Bill saw__)?' 'Ann, I think he told me he tried to like

Determinamos o IEP e revisamos as evidências contra recursividade sintática em Pirahã. Falta agora demonstrar como se encaixam em uma relação causal. Descobri que eles se engajam como numa roda dentada, por meio da evidencialidade. Pirahã, como muitas outras línguas (inter alia, AIKHENVALD, 2003; FALLER, 2007), codifica marcadores evidenciais em sua morfologia verbal, como afixos: -híai 'hearsay,' -sibiga 'deduction;' -ha 'complete certainty,' e -0 (zero affix) 'assumption of direct knowledge'. O IEP Pirahã, com a necessidade de haver evidência para todas as afirmativas, produz um domínio estreito, no qual as afirmações e seus constitutivos precisam ser aceitos. Reportando-me ao Potential Focus Domain de Van Valin (2005), chamo esse domínio em Pirahã (presumidamente alguma versão disso existe em todas as línguas, ao menos naquelas com morfologia através da evidencialidade) de DOMíNIO DA EVIDENCIALIDADE POTENCIAL (POTENTIAL EVIDENTIALITY DOMAIN - PED), i.e., a gama de estruturas nas quais poderia recair, em princípio, o 
domínio real da evidencialidade. O domínio real da evidencialidade em certo enunciado será da seguinte forma:

DOMÍNIO DA EVIDENCIALIDADE: O domínio sintático em uma oração que expressa o componente da evidencialidade de uma proposição estruturada pragmaticamente.

O PED em Pirahã é limitado à estrutura lexical do verbo, i.e., o verbo e seus argumentos (mais tecnicamente, o núcleo do sintagma do predicado e seus argumentos, na terminologia de Van Valin em Role and Reference Grammar). ${ }^{19}$ Vamos presumir que IEP é uma das razões pelas quais o Pirahã tem marcadores de evidencialidade, e que isso fortalece significantemente seu efeito, ao limitar seu escopo ao PED mencionado.

O PED então exclui recursividade sintática em Pirahã. Conforme apontado, o PED claramente depende do verbo principal, como centro do ato de fala. O PED inclui apenas o núcleo (núcleo semântico-sintático, não núcleo no sentido da teoria X-Barra) diretamente licenciados pelo predicado (sua estrutura semântica). Nenhum núcleo pode ficar fora do PED de uma oração.

Pelo PED não há possuidores encaixados; não há predicados encaixados - há somente argumentos licenciados pelo predicado principal. Por exemplo, numa locução nominal como "John's house", "house" é o núcleo - o centro semântico, sobre o qual é a locução. John é o possuidor, um tipo de modificador do núcleo "house" - o possuidor nos diz sobre que casa estamos falando. Por outro lado, numa locução nominal maior como "John's brother's house", "house" e "brother" são, cada um, um núcleo de uma locução separada. "House" é o núcleo da locução "brother's house" e "brother" é o núcleo da locução "John's brother". "John” não é um núcleo de nenhuma locução. Isso significa que 'John', não sendo o possuidor de um argumento do verbo principal (é o núcleo de 'John's brother' mas 'brother' não é núcleo do verbo) não é aceita no PED e a oração é rejeitada. Um predicado encaixado conteria argumentos não licenciados pelo predicado principal. Portanto, não pode haver locuções dentro de locuções e nem orações dentro de orações em Pirahã. Tampouco pode haver composição produtiva na morfologia. Essas composições aparentes são, na verdade, locuções sincrônicas ou diacrônicas.

Isso está exemplificado abaixo, numa representação livre da influência de teorias específicas:

19 Utilizo Role and Reference Grammar aqui porque considero que essa gramática mais eficazmente mistura os princípios estruturais e semânticos-funcionais para fazer uma teoria de gramática. Nada essencial está preso aqui, no entanto, e outras teorias talvez sejam compatíveis com a análise apresentada aqui. 


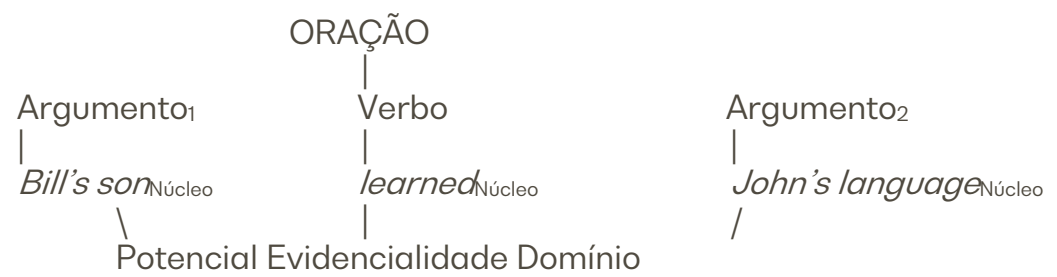

Esse exemplo é permitido porque cada núcleo é encontrado na estrutura semântica do verbo, representado nas linhas da seguinte representação léxica: [BECOME know (son, language)]. Esse é um requisito bastante rígido da evidencialidade. Prevê que o número de argumentos numa oração não pode exceder o número permitido pela estrutura verbal padrão (e.g. RRG). Exclui todos os encaixes e toda a recursividade sintática.

A representação lexical de um verbo télico ("accomplishment verb”), e.g. 'learn'([BECOME know] indica a mudança do estado do conhecimento) projeta três núcleos para a sintaxe - o verbo 'learn', e os núcleos/argumentos nominais 'son' e 'language'. Cada um dos núcleos nominais é objeto de posse de um elemento nominal que não é núcleo. Assim são preenchidos os requisitos do PED. Entretanto, no exemplo abaixo, há dois núcleos não aceitos, i.e., que aparecem no PED sem serem encontrados na representação lexical:

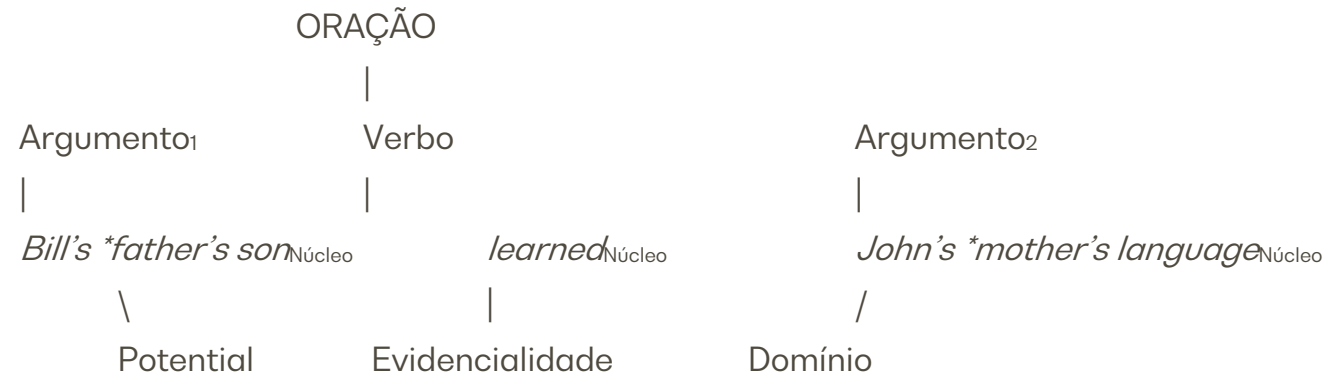

Essa oração seria, portanto, contrária à gramática Pirahã, apesar de ser válida em inglês. "father's" e "mother's" não estão dentro do escopo dos evidenciais no verbo porque são núcleos, não meramente possuidores, e não estão explicitamente elencados na estrutura lexical do verbo. Minha análise defende que a existência de evidenciais, seu escopo e, consequentemente, a falta de recursividade, são todos reflexos do valor cultural IEP na gramática Pirahã.

Embora o PED (forçado pelo IEP) exclua recursividade em Pirahã, minha análise não requer que qualquer outra língua, e.g. Riau (GIL, 1994), necessariamente derive na ausência da recursividade da mesma forma. A recursividade tem vários propósitos (EVERETT, 2012) e, assim, há mais de uma razão por que uma língua talvez use ou não use recursividade em sua sintaxe sentencial. Por exemple, Riau talvez simplesmente classifique um valor de taxa de informações mais lentas, acima de um valor que favorece orações recur- 
sivas em sua língua. Muitas tradições orais usam repetição e taxa de informações mais lentas como auxílios na comunicação em ambientes barulhentos da fala humana. Portanto, isso é uma explicação cultural de alguns fatos sintáticos muito complexos que afetam, de forma geral, a língua Pirahã.

Everett (2005, p. 2) concluiu, assim, que a cultura da língua Pirahã afeta sua gramática:

\footnotetext{
[...] a conclusão é séria - alguns dos componentes da chamada gramática central estão sujeitos a limitações culturais, algo que se prevê que não ocorra de acordo com o modelo de gramatica universal. Argumento que esses fatores aparentemente desarticulados sobre as lacunas da língua Pirahã, que são muito surpreendentes de quase qualquer perspectiva gramatical, derivam de uma única restrição cultural em Pirahã, a saber, a limitação da comunicação para a experiência imediata dos interlocutores.
}

Isso resultou em mais de uma década de controvérsias. (inter alia, EVERETT 2008, 2009, 2010a, 2010b, 2012a, 2012b, 2013a, 2013b, 2014a, 2014b). A palavra final no assunto, por ora, novamente, a partir de pesquisas independentes, é Futrell et. al. (2016). Nesse trabalho meus coautores e eu argumentamos que não há evidência clara de estruturas recursivas, partículas de coordenação conjuntivas ou disjuntivas etc., em uma amostra de muitos textos coletados por mim e por Steve Sheldon, missionário que trabalhou cerca de dez anos entre os Pirahã e ainda fala a língua deles com fluência. Em, inter alia, Everett (2005, 2009, 2010a, 2010b, 2012a, 2012b), apresento mais evidências e explico essa falta recursividade em termos de fluxo de informações e um valor cultural geral, que nomeio "Imediatidade da Experiência". Argumento, com detalhes, nesses e em outros estudos, que esse valor explica melhor uma variedade de aspectos da cultura e língua Pirahã, como a falta de textos ficcionais e históricos, o mais simples parentesco já documentado, a ausência de tempos verbais perfeitos, entre outras coisas. De fato, o tema de todos esses trabalhos é que a cultura é inseparável do entendimento da cognição Pirahã.

\section{A ANTROPOLOGIA DAS ORIGENS DA LÍNGUA(GEM)}

Num trabalho mais recente (EVERETT, 2017), argumento que as evidências arqueológicas sustentam a tese de que o Homo erectus inventou a língua(gem) e que o fez desenvolvendo uma simbiose entre cultura e língua.

A base da língua(gem), em meu entendimento, é o símbolo, a combinação de uma forma, acordada pela cultura, com um significado desenvolvido culturalmente. As restrições perceptuais humanas e suas limitações de pensamento guiam esse processo, mas ele é, em grande parte, a produção das sociedades humanas, seus valores, seus conhecimentos e suas estruturas sociais.

Para Peirce, um símbolo era bem diferente do que um "signo" era para Saussure. Os símbolos são triádicos e recursivos. Os signos são diádicos e não-recursivos. Um símbolo 
codifica a relação entre um objeto, um interpretante (o efeito do objeto no ouvinte, mais ou menos similar a uma interpretação), e uma forma. Convencionou-se que a forma liga o objeto ao interpretante. Isso se torna crucialmente diferente dos signos diádicos de Saussure, que são simplesmente pares de forma/significado, no sentido de que, apesar de animais não humanos poderem reconhecer e produzir signos, não está claro se eles podem reconhecer ou produzir símbolos. O motivo é que um interpretante de um símbolo é também um tipo de signo, que também faz surgir um interpretante, e assim por diante, recursivamente. Interpretantes somente podem ser entendidos como parte da cultura. São mais do que meras respostas. Indicam a rede abstrata da interpretação que só vem à tona por meio de uma cultura. Consequentemente, o aparecimento de símbolos, no sentido de Peirce, indica o nascimento da língua(gem), mas a existência de signos é comum no reino animal (provavelmente no reino vegetal também), e não é, por si, indicativa de existência da língua (Everett no prelo, inter alia).

Presumindo que isso está correto, e que o símbolo é a linha divisória linguística entre humanos e outras criaturas, produzimos uma simples distinção entre os sistemas de comunicação de não humanos e humanos (de todas as espécies do Homo através do tempo, segundo EVERETT, 2017):

COMUNICAÇÃo é a transferência de informações (grosso modo, para fins de discussão, algo contingente, externo ao organismo que afeta o comportamento do organismo).

LINGUA(GEM) é a transferência de informações por meio de símbolos. ${ }^{20}$

Linguistas formais talvez contestem, já que há muito tempo foi presumido que as línguas são definidas pelas gramáticas, particularmente na hierarquia de Chomsky de gramáticas (CHOMSKY, 1959). No entanto, é interessante que, num trabalho recente, um linguista formal na esteira de Chomsky parece concordar (MURPHY, 2015):

\footnotetext{
Foi demonstrado que a operação Label, não a Merge, constitui a novidade evolutiva que distingue linguagem humana de sistemas computacionais não humanos; uma proposta que dá peso a uma Hipótese de Continuidade Fraca, e que levou à formação do que é chamado de Etologia Computacional.
}

Símbolos, no sentido de Pierce que usamos aqui, são triádicos, inerentemente itens recursivos que incluem todas as tríades forma-significado-interpretações em uma língua.

20 Logicamente a gramática é importante porque é a "embalagem" necessária para os símbolos. Discuto isso logo adiante. É importante observar que, segundo a perspectiva de Pierce (EVERETT, no prelo a), a gramática é parte de uma estrutura simbólica de qualquer língua(gem). 
A gramática é inerente em qualquer gramática semiótica, apesar de ser diferente (ver abaixo) talvez do que é presumido em alguns escritos formais. Quanto à origem, os símbolos provavelmente resultaram em parte da associação de dois objetos por engano, por exemplo uma raiz de árvore confundida com uma serpente, ou simplesmente pela associação normal de uma coisa no mundo com outro objeto ou evento, como o cachorro de Pavlov aprendeu a associar alimento ao toque de um sino. Feita a conexão, os humanos começaram a usar os símbolos, aprendendo uns com os outros. Uma vez que a comunicação é um esforço do ser por inteiro, gestos, entonação, pulmões, boca, língua, mãos, movimentos corporais, e até as sobrancelhas foram moldadas para uso na língua(gem), assim como são em muitas outras comunicações entre animais. Esses diferentes componentes de nosso esforço comunicativo na língua(gem) teria dividido símbolos em partes cada vez menores, assim como também foram usados para construí-los em unidades cada vez maiores. Sons da fala, palavras, orações, afixos gramaticais, e tons emergiram todos da invenção inicial do símbolo - os símbolos são melhorados, adotados, e disseminados ao longo do tempo pelo envolvimento da sociedade, assim como todas as outras invenções. Elementos sem sentido (sons como " $s$ ", " $a$ " e " $t$ ") foram reunidos para formar itens significativos (como a palavra "sat") e "dualidade de padronização" surgiu com o símbolo, levando a três tipos de gramáticas. O primeiro tipo de gramática, $\mathrm{G}_{1}$, é pouco mais que símbolos, dispostos em filas como contas num colar: "Eat. Drink. Man. Woman". Ou até mesmo “/ see you. You see me?'. O segundo tipo, $\mathrm{G}_{2}$, dispõe símbolos linearmente (em fila), como a gramática $\mathrm{G}_{1}$, mas também hierarquicamente - combinando símbolos dentro de outros símbolos, como muitas línguas modernas europeias fazem (e.g. [[The man [with the red hair] arrived]]. O terceiro tipo de gramática, $\mathrm{G}_{3}$, faz tudo que os outros tipos fazem, mas adicionando a propriedade de múltiplos encaixes de estruturas. Os três tipos de língua(gens) ainda são encontrados no mundo. Todas são totalmente funcionais, e são adequadas para diferentes nichos culturais. Comunidades Homo erectus falavam um ou todos esses tipos de gramáticas, em seus locais remotos ao redor do mundo. ${ }^{21}$

Evidências de que o erectus tinha língua(gem) são apresentadas em Everett (2016, 2017), a partir de seus padrões de povoamento, viagens, navegação e transporte de ferramentas. Não revisarei todas as evidências novamente aqui, mas os leitores têm as referências para os dados.

21 As gramáticas $G_{1}, G_{2}$, e $G_{3}$ são ortogonais, na hierarquia chomskyana de gramáticas. A primeira se refere somente a formas superficiais, e são voltadas para mostrar que as gramáticas semióticas/simbólicas não precisam ser tão complicadas, como se poderia pensar que tivessem que ser, para serem consideradas gramáticas de verdade. A razão pela qual são ortogonais na hierarquia de Chomsky é que qualquer uma delas poderia ser gerada por qualquer gramática na hierarquia, na ausência de evidência concreta. 
As língua(gens) humanas se modificam com o tempo e com as culturas, e os falantes as sofisticam em alguns lugares e as simplificam em outros. Portanto, as língua(gens) contemporâneas são em seus detalhes, assim, diferentes da que existia há dois milhões de anos. Porém, é fato que há dois milhões de anos na África, uma comunidade Homo erectus começou a compartilhar informações entre seus membros, por meio da língua(gem). Foram os primeiros a dizer "It's over there", "I am hungry". Talvez tenham sido os primeiros a dizer "/ love you". Eles conquistaram isso ao desenvolver cultura, símbolos e gramática, o que levou à primeira revolução cognitiva e informacional, na história de nossa espécie.

As comunidades Erectus eram diferentes das comunidades sapiens, de diversas formas. Entretanto, todas as evidências sugerem semelhanças com outras sociedades de seres humanos, provavelmente envolvendo discussões, deliberações, debates e queixas, pois viajavam o mundo e legaram a nós sua invenção, a língua(gem).

Cada ser humano vivo desfruta de sua gramática e de sua sociedade por causa do trabalho, das descobertas e da inteligência do Homo erectus, desenvolvendo cultura e língua como a maior simbiose cognitiva. A seleção natural pegou as coisas mais eficazes para a sobrevivência humana e aperfeiçoou a espécie. Hoje os humanos vivem na era da inovação, na era da cultura, no reino da fala.

\section{METODOLOGIA E DIRECIONAMENTOS FUTUROS}

Em trabalhos futuros, há necessidade de explorar as conexões entre a matéria escura da mente e o programa de pesquisa do Behaviorismo, prematuramente abandonado (por muitos cognitivistas), principalmente a versão da teoria desenvolvida por Staddon (2014). Não é um abandono dos objetivos das ciências cognitivas, nem da cognição, de maneira mais geral. O Behaviorismo, afinal de contas, nunca abandonou o objetivo de entender a mente. É, ao contrário, um reconhecimento de que o comportamento externo - o processo cultural e lingualização, por exemplo -, é nossa única evidência para a mente.

Um motivo pelo qual não dão certo as tentativas de desenvolver modelos do papel da cultura na cognição é que faltam componentes metodológicos que possibilitariam que outros os testassem e os desenvolvessem mais, por meio de pesquisas interculturais e interlinguísticas. Concluirei com uma lista de alguns desiderata para entender os componentes das culturas:

1. Os componentes devem poder ser aprendidos a partir do ambiente (já que todas as pessoas têm cultura, e as culturas variam e se sobrepõem de maneiras interessantes). Isso é muitas vezes ignorado em ciências cognitivas modernas, conforme aponta 
Blumberg (2006), por exemplo. Quando presumimos, a partir do início, que algo é, de forma inata, "pobreza de estímulo", os argumentos tornam-se circulares. Pode-se sempre concluir que uma certa parcela de conhecimento ou habilidade, etc., é natural. Porém, isso deve ser descoberto, e não presumido.

2. Os componentes, de forma ideal, têm uma trajetória evolutiva clara. O ônus da prova - para quem alega que um comportamento particular, por mais comum ou inicial na história de vida de um sujeito, é parte do genoma, por exemplo - é fornecer um relato sólido das pressões seletivas (inclusive população, ecologia contemporânea, criaturas concorrentes, etc.) que possam representar a evolução de um traço particular. Conforme argumentou Everett (2017), as mutações são, de modo geral, explicações baseadas em presunções questionáveis de catastrofismo, e não presunções sólidas de uniformitarianismo de processos evolutivos (o que não é, de forma alguma, alegar que as mutações talvez não existam. Porém, novamente, deve haver descobertas, e não presunções).

3. Devem ser suficientemente sólidas de modo que possibilitem variação em vários níveis. Por exemplo, reconsiderando os experimentos na visão e percepção entre os $\mathrm{Pi}$ rahã, eles poderiam ser estendidos por uma gama de outros tipos de testes de visão, em vez de simplesmente juntar todas as percepções visuais em uma única categoria. Além disso, seria útil fazer testes adicionais, por exemplo, com sujeitos estadunidenses numa variação mais ampla de tarefas de percepção, tais como sua percepção auditiva vs. percepção auditiva de caçadores-coletores, tipos de percepção auditiva (música vs. sons zoológicos), bem como tipos diferentes de percepção visual (como percepção de áreas abertas, para pessoas criadas num deserto, por exemplo, vs. percepção visual das mesmas áreas abertas para habitantes da selva que raramente experienciam espaços muito abertos).

4. Devem ser testáveis. Todos os exemplos e alegações neste trabalho são testáveis. Foram feitos de tal forma que sabemos o que precisa ser feito para que cursem sua trajetória empírica.. Se há uma alegação a respeito de linguagem, como pode ser testada, além dos valores-p em experimentos isolados, por exemplo? Podemos encontrar evidências de compreensão de estruturas sintáticas específicas ou domínios semânticos em discurso natural ou conversação, ou outros comportamentos? Descobri, por exemplo, que, apesar de os Pirahã serem capazes de ordenar as pastilhas de Munsell em pilhas, de maneiras semelhantes às criadas por sujeitos estadunidenses, eles simplesmente não usam os termos ou as distinções em conversações que ocorrem de maneira natural. "Testável", no meu sentido, portanto, refere-se a uma variedade de 
testes. A psicologia está em crise de certa forma porque tem dependido muito de experimentos breves de laboratório, e não o suficiente em pesquisa de campo que leva em consideração um entendimento sério da cultura dos sujeitos.

5. Devem nos possibilitar entender como a cultura e a cognição "se conectam". Psicólogos e antropólogos frequentemente conversam, acreditando que suas ideias são semelhantes, embora sejam, na verdade, diferentes. Um antropólogo pode descrever uma cultura como adversa a certos tipos de atividades, como contar. Ou um psicólogo pode realizar experimentos que parecem mostrar uma habilidade de contar. No nosso trabalho com Pirahã, observamos que às vezes os Pirahã parecem ser capazes de contar, diferenciando "dois peixes" de "um peixe". Porém, notamos que, ao observar as palavras que pensei significarem "um" vs. "dois", elas na verdade significavam "pequeno" e "um pouco mais". Dois peixes pequenos, por exemplo, quando comparados ao peixe grande, eram descritos como o que inicialmente parecia ser "um", ao passo que o peixe maior foi descrito pela palavra que pensei significar "dois". Mais adiante, em textos, foi descoberto que um bebê do sexo masculino, por exemplo, é um "homem pequeno", mas eu havia pensado que a palavra "pequeno" significasse "um". O contexto cultural, a fluência linguística, e o conhecimento da vida nas vilas, para citar alguns exemplos, podem ser fatores vitais na psicologia intercultural ou de subgrupo intersocial.

6. Devem ser úteis, de forma explanatória. Por exemplo, pode-se dizer que os parisienses gostam de boa comida, e que ao mesmo tempo desejam ter boa forma. Porém, eu pensaria o mesmo de pessoas de Detroit. Um estudo mais detalhado poderia revelar diferenças de ranking, tais como poderia ser mais importante para os parisienses estarem em forma do que a boa comida, enquanto que para as pessoas de Detroit o ranking é o inverso. Esse exemplo rudimentar, indubitavelmente errôneo e simplista de ranking, é o motivo pelo qual nossas análises da cultura precisam ser sólidas e testáveis por uma série de critérios.

Everett (2016) é uma tentativa constante de realizar essas desiderata e fornecer um modelo para investir na cognição de maneira intercultural. Particularmente, no entanto, chamo a atenção do leitor, mais uma vez, para a seção acima sobre Evidencialidade e sua interface com a cultura (especialmente o princípio Imediatidade da Experiência) em Pirahã. Essa seção e a seção de fonologia ilustram como um estudo independente de uma cultura particular pode iluminar questões que de outra forma poderiam ser consideradas puramente linguísticas, por mais incomuns que fossem. Ao colocar a fonologia e a mor- 
fossintaxe no modelo apropriado de uma cultura particular, espero que tais seções tenham ilustrado como os métodos sugeridos podem ser úteis para o linguista, especialmente para o pesquisador de campo.

Logicamente nem todos concordarão com a abordagem que sugiro em meu livro. Entretanto, espera-se que, qualquer que seja o modelo assumido, desenvolvido, ou criticado, ocorram mais pesquisas sobre o papel da cultura na cognição. De fato, há evidências de que esta é uma promissora nova linha de pesquisa. Gibson et. al. (2017) argumenta que dar nome às cores é inerentemente um fenômeno cultural, ao menos parcialmente inspirado pelo trabalho de Everett (2005).

\section{CONCLUSÃO}

Neste panorama geral, apresentei evidências de que a cognição humana, da linguagem à memória e à percepção, é profundamente afetada pela cultura humana. Ofereci definições de cultura e seu motor subjacente, matéria escura da mente, de acordo com pesquisas minhas em andamento, relatadas particularmente em Everett (2012, 2016, e 2017). Os humanos são criaturas culturais. Não podemos entender a nós mesmos na ausência de um conceito claro de cultura e de como isso é endossado pelas pessoas.

\section{REFERÊNCIAS}

AIKHENVALD, Alexandra Y. Language Contact in Amazonia. Oxford: Oxford University Press, 2003.

AMARAL, Luiz; MAIA, Marcus; NEVINS, Andrew; ROEPER, Tom (Eds). 2018. Recursion Across Domains, Cambridge: Cambridge University Press, 2018.

BLUMBERG, Mark S. Basic Instinct. The Genesis of Behavior. Nova lorque: Basic Books, 2006.

BOYD, Robert; RICHERSON. Peter. The Origin and Evolution of Cultures. Oxford: Oxford University Press, 2005.

BOYD, Robert; RICHERSON, Peter J. Culture and the Evolutionary Process. Chicago: University of Chicago Press, 1988.

BRANDOM, Robert. Making it Explicit. Reasoning, Representing, and Discursive Commitment. Cambridge: Harvard University Press, 1994.

CHOMSKY, Noam. Knowledge of Language: Its Nature, Origins, and Use. Santa Barbara, California: Praeger, 1986.

BARKOW, Jerome H.; COSMIDES, Leda; TOOBY, John (Eds.). The Adapted Mind: Evolutionary Psychology and the Generation of Culture. Oxford: Oxford University Press, 1992.

DOBZHANSKY, Theodore. Mankind Evolving: The Evolution of the Human Species. Connecticut: Yale University Press, 1962.

EVERETT, C.; MADORA, K. (2012). "Quantity Recognition Among Speakers of an Anumeric Language". Cognitive Science, 36: 130-141. 
EVERETT, C.. Numbers and the Making of Us: Counting and the Course of Human Cultures. Cambridge: Harvard University Press, 2017.

EVERETT, D. L. (2005). "Cultural Constraints on Grammar and Cognition in Pirahã: Another Look at the Design Features of Human Language”. Current Anthropology, 76: 621-646.

EVERETT, D. L. Don't sleep, there are snakes: life and language in the Amazonian jungle. Nova lorque: Pantheon, 2008.

EVERETT, D. L. (2009). “Pirahã Culture and Grammar: A Response to Some Criticisms”. Language, 85: 405-442.

EVERETT, D. L. (2010a). “You Drink. You Drive. You Go to Jail. Where’s Recursion?”. Disponível em: http://ling.auf.net/lingbuzz/@tCyulTrPicSKpoXb/wbOhgtZe?137.

EVERETT, D. L. (2010b). “The Shrinking Chomskyan Corner in Linguistics”. Dispnível em: http://ling.auf.net/lingbuzz/000994

EVERETT, D. L. Language: The Cultural Tool. Nova lorque: Pantheon Books, 2012a.

EVERETT, D. L. (2012b). "What does Pirahã Have to Teach Us About Human Language and the Mind?". WIREs Cogn Sci, 3: 555-563. DOI: DOI.ORG/10.1002/WCS.1195.

EVERETT, D.L. (2013a). “A Reconsideration of the Reification of Linguistics”. September 26, The Cognitive Revolution, 60 Years at the British Academy, London.

EVERETT, D.L. (2013b). “'The State of Whose Art?' Reply to Nick Enfield's Review of Language: The Cultural Tool'. Journal of the Royal Anthropological Institute, 19: 645-648.

EVERETT, D.L. “The Role of Culture in Language Emergence”. In: MACWHINNEY, Brian; O'GRADY, William. The Handbook of Language Emergence: Wiley-Blackwell, 2014a.

EVERETT, D.L. "Concentric Circles of Attachment in Pirahã: A Brief Survey". In: KELLER, Heid; OTTO, Hiltrud (Eds.). Different Faces of Attachment: Cultural Variations of a Universal Human Need. Cambridge: Cambridge University Press, 2014b.

EVERETT, D.L.. Dark Matter of the Mind: The Culturally Articulated Unconscious. Chicago: University of Chicago Press, 2016

EVERETT, D.L. How Language Began: The Story of Humanity's Greatest Invention, Nova lorque: Liveright-W.W. Norton, 2017.

EVERETT, D.L. (In Progress A). Peircean Linguistics: A Chapter in the History of Empiricist Thought. Oxford: Oxford University Press.

EVERETT, D.L. (In Progress B). “Review of Recursion Across Domains”.

EVERETT, D.L.; EVERETT, K. (1984). “On the Relevance of Syllable Onsets to Stress Placement”, Linguistic Inquiry, 15: 705-711.

FALLER, Martina (2007). “The Cusco Quechua Reportative evidential and Rhetorical Relations”. Endangered Languages: Linguistische Berichte Sonderheft (Special Issue), 14: 223-251.

FEDORENKO, E.; FRANK, M.C.; EVERETT, D.; GIBSON, E. (2011). "Differential Effects of Culture on Phonological And Spatial Short-Term Memory: a Comparative Investigation of an Amazonian Tribe and US Participants". Unpublished MS, MIT.

FRANK, M.; EVERETT, D.L.; FEDORENKO, E.; GIBSON, E. (2008). "Number as a Cognitive Technology: Evidence from Pirahã Language and Cognition”. Cognition, 108: 819-24.

FUTRELL, R.; PIANTADOSI, S. T.; STEARNS, L.; EVERETT, D.L.; GIBSON, E. (2016). “A Corpus Analysis of Pirahã Grammar: an Investigation of Recursion". Plos One, 11(3): DOI.ORG/10.1371/JOURNAL.PONE.0145289 
GIBSON, E.; FUTRELL, R.; JARA-ETTINGER, J.; MAHOWALD, K.; BERGEN, L.; RATNASINGAM, S.; GIBSON, M.; PIANTADOSI, S. T.; CONWAY, B. (2017). "Color Naming Across Languages Reflects Color Use”. PNAS, 114 (40): 1078510790. DOI: $10.1073 /$ PNAS.1619666114.

GIL, David (1994). "The structure of Riau Indonesian”. Nordic Journal of Linguistics, 17: 179-200.

GODDARD, Cliff. "Ethnosyntax, Ethnopragmatics, Sign Functions, and Culture". In: ENFIELD, N.J. (Ed.). Ethnosyntax: Explorations in Grammar and Culture. Oxford: Oxford University Press, 2002: 52-73.

GORDON, P. (2004). "Numerical Cognition Without Words: Evidence from Amazonia”. Science, 306: 496-499.

HALL, E. T. The Silent Language. Nova lorque: Anchor Books, 1973 [1959].

HALL, E. T. Beyond Culture. Nova lorque: Anchor Books, 1976.

HALL, E. T. The Hidden Dimension. Nova lorque: Anchor Books, 1990.

HAUSER, Marc; CHOMSKY, Noam; FITCH, Tecumseh (2002). "The Faculty of Language: What Is It, Who Has It, How Did It Evolve?”. Science, 298: 569-1579.

HEADLAND, T. (1990). “Emics and Etics: The Insider/Outsider Debate”. The Journal of American Folk/ore, 75: 95-105.

HOOKWAY, Christopher. "Indeterminacy and Interpretation". In: HOOKWAY, Christopher; PETTIT, Philip (Eds.), Action and Interpretation: Studies in the Philosophy of the Social Sciences. Cambridge: Cambridge University Press, 1978 : $17-41$.

HYMES, D. Foundations in Sociolinguistics: An Ethnographic Approach. Philadelphia: University of Pennsylvania Press, 1974.

KESSELS, R. P. C. ; VAN ZANDVOORT, M. J. E. ; POSTMA, A.; KAPPELLE, L. J. ; DE HAAN, E. H. F. (2000). "The Corsi Block-Tapping Task: Standardization and Normative Data". Applied Neuropsychology, 7: 252-258.

KUPER, A. Culture: The Anthropologists'Account, Cambridge, Massachusetts: Harvard University Press, 2000.

LANGACKER, Ronald W. Concept, Image, and Symbol. Berlim: Mouton DeGruyter, 1994.

LEVINSON, S. (2012). "The Original Sin of Cognitive Science". Topics in Cognitive Science, 4: 396-403.

MURPHY, Elliot. (2015). "Labels, Cognomes, and Cyclic Computation: An Ethological Perspective". Frontiers in Psychology, 6: 715. DOI.ORG/10.3389/FPSYG.2015.00715

NEVINS, Andrew; PESETSKY, David; RODRIGUES, Cilene (2009). “Pirahã Exceptionality, a Reassessment”. Language, 85: 355-404.

NEWMAN, John. "Culture, Cognition, and the Grammar of 'Give' Clauses”. In: ENFIELD, N.J. (Ed.). Ethnosyntax: Explorations in Grammar and Culture. Oxford: Oxford University Press, 2002: 74-98.

PERFORS, Amy; TENENBAUM, Josh B.; GIBSON, Edward; REGIER, T. "How Recursive Is Language? A Bayesian Exploration”. In: VAN DER HULST, Harry (Ed). Recursion and Human Language. Berlim: Mouton DeGruyter, 2010: 159175 .

PIKE, K. L. Language In Relation to a Unified Theory of the Structure of Human Behavior (Janua Linguarum, Series Maior, 24). The Hague: Mouton, 1967 [Second Rev. Ed.].

PINKER, Steven. The Language Instinct: How the Mind Creates Language. Nova lorque: William Morrow \& Co, 1994.

POLANYI, M. Personal Knowledge:Towards a Post-Critical Philosophy. Chicago: University of Chicago Press, 1974.

POLANYI, M. The Tacit Dimension. Chicago: University of Chicago Press, 2009 [1966].

SAPIR, Edward. Language: An Introduction to the Study of Speech. San Diego: Harcourt, Brace, and Company, 1921.

SEARLE, J. Intentionality: an Essay in the Philosophy of Mind. Cambridge: Cambridge University Press, 1983. 
SEARLE, J. (1980a). "'Las Meninas and the Paradoxes of Pictorial Representation”. Critical Inquiry, Vol. 6, N. 3: 477488

SEARLE, J. (1980b). “Minds, Brains and Programs". Behavioral and Brain Sciences, 3(3): 417-457. DOI: 10.1017/S0140525X00005756,

SEARLE, J. The Mystery of Consciousness. Nova lorque: New York Review of Books, 1997.

SEEMAN, Axel (Ed.) Joint Attention: New Developments in Psychology, Philosophy of Mind, and Social Neuroscience. Cambridge, Massachusetts: MIT Press, 2012.

SONTAG, S. Susan Sontag: Essays of the 1960s and 70s. Nova lorque: Library of America. 2013 [1973].

SPERBER, Dan; HIRSCHFELD, Lawrence A. (2004). "The Cognitive Foundations of Cultural Stability and Diversity". Trends in Cognitive Science, 8: 40-46.

Staddon, J. The New Behaviorism. 2 ${ }^{\text {ND }}$ Edition. East Sussex: Psychology Press, 2014.

WIERZBICKA, Anna. Semantics, Culture, and Cognition: Universal Human Concepts in Culture-Specific Configurations. Oxford: Oxford University Press, 1992.

WIERZBICKA, Anna. Understanding Cultures Through Their Key Words: English, Russian, Polish, German, Japanese. Oxford: Oxford University Press, 1997.

WIERZBICKA, Anna. Imprisoned in English: The Hazards of English as a Default Language. Oxford: Oxford University Press, 2014.

WNUK, E.; MAJID, A. (2014). "Revisiting the Limits of Language: The Odor Lexicon of Maniq”, Cognition, 131: 125-138.

YOON, J. M. D.; WITTHOFT, N.; WINAWER, J.; FRANK, M. C.; EVERETT, D.L.; GIBSON, E.. (2014). "Cultural Differences in Perceptual Reorganization in US and Pirahã Adults”, Plos One, 9(11). DOI.ORG/10.1371/JOURNAL.PONE.0110225 